\title{
El deber de la administración pública de resolver el procedimiento administrativo: ¿Nueva regulación española en la Ley 39/2015 del Procedimiento Administrativo Común de las Administraciones Públicas?
}

\author{
The public administration duty to resolve the administrative procedure: \\ New regulation in the Spanish Law 39/2015 of the Common Administrative Procedure for \\ the Public Administrations?
}

\author{
Humberto Gosálbez Pequeño \\ Universidad de Córdoba, España
}

\begin{abstract}
RESUMEN En España, la Ley 39/2015 impone a la administración pública la obligación de resolver expresamente el procedimiento administrativo antes del vencimiento de un plazo máximo legalmente establecido. Excepcionalmente, la Ley 39/2015 admite algunas causas de suspensión temporal del plazo máximo de resolución y de notificación de la resolución expresa del procedimiento.
\end{abstract}

PALABRAS CLAVE Administración pública, procedimiento administrativo, resolución administrativa expresa, plazo máximo de resolución, notificación del procedimiento administrativo

ABSTRACT In Spain, Law 39/2015 imposes the obligation on the public administrations to expressly resolve the administrative procedure before the expiration of a legally established maximum term. Exceptionally, Law 39/2015 admits some causes of temporary suspension of the maximum period for issuing and notifying an express administrative resolution.

KEYWORDS Public administration, administrative procedure, express administrative resolution, maximum deadline for resolution, notification in administrative procedure 


\section{El fundamento institucional y la concepción del deber legal de resolver el procedimiento administrativo}

\section{¿Reconocimiento constitucional implícito?}

El deber de la administración pública de resolver los procedimientos administrativos no tiene, como es sabido, explícita previsión constitucional. Y tampoco la Constitución reconoce el derecho del ciudadano a la resolución administrativa expresa en plazo, sino solo - y no es poco en 1978 - el derecho al previo procedimiento administrativo con audiencia (artículo 105 letra c) de la Constitución Española, 1978); es decir, el derecho del administrado a una resolución administrativa expresa «en plazo» en modo alguno es un derecho constitucional, sino que es un derecho ex lege amparado, sí, en derechos y principios constitucionales ${ }^{1}$ como es, relevantemente, el dispuesto en el artículo 105 letra c). ${ }^{2}$

Es cierto, no obstante, que este derecho del ciudadano -y deber de la Administración ${ }^{3}$ tiene un expreso reconocimiento en la Carta de los Derechos Fundamentales de la Unión Europea y también en los Estatutos de Autonomía, por cuanto han positivizado el principio jurisprudencial comunitario de «buena administración» que, sin duda, incluye el derecho al procedimiento administrativo «debido» (Ponce Solé, 2001: 147 y ss. $)^{4} y$, en consecuencia, el deber de resolver expresamente los procedimientos administrativos. Pero estas normas, aun cuando establecen el deber de la resolución administrativa expresa, la exigen en un plazo razonable — «concepto jurídico indeterminado que es, debe o debería ser concretado", como afirma Pérez Monguió (2014: 312-313)—, no en un plazo máximo. El deber administrativo de resolver dentro de un plazo deter-

1. Por ello Rivero Ortega (2012: 143-144) afirma incluso que «el incumplimiento de la obligación de resolver por la Administración supone una trasgresión de su posición constitucional y su propia esencia», o, en otros términos, «una Administración que no resuelve es incompatible con nuestro marco constitucional». En el mismo sentido, más recientemente se ha manifestado Rivero Ysern (2016: 173-176).

2. Entre los principios constitucionales fundamentadores de este deber legal de administración destaca el principio de seguridad jurídica, como ha explicado, entre otros, Alonso Ibáñez (2012: 186); así mismo lo alega Cantero Martínez (2007: 1.504-1.505), quien, además, añade el principio constitucional de eficacia administrativa.

3. El legislador continúa calificándolo de «obligación», tanto en el artículo 42 de la Ley de España 30/1992 como en el artículo 21 de la Ley 39/2015, pese a que la generalidad de la doctrina lo conceptúa como un deber. Véase Rivero Ortega (2012: 151-152) y Gómez Puente (2000: 485 y ss.).

4. Así mismo lo han resaltado Rivero Ortega (2012: 140) y Alonso Ibáñez (2012: 185-186). Y más genéricamente, refiriéndose a la inactividad administrativa y no solo al deber de resolver -y por ello, acertadamente, a nuestro juicio- lo ha subrayado Gómez Puente (2012: 27 y ss.).

5. La Carta de los Derechos Fundamentales de la Unión Europea (2000), en su artículo 41, dispone el siguiente contenido esencial del «derecho a una buena administración»: «1. Toda persona tiene derecho a que las instituciones y órganos de la Unión traten sus asuntos [...] dentro de un plazo razonable $[\ldots]$ ». Y, por ejemplo, la Ley Orgánica 2/2007, de 19 de marzo, de Reforma del Estatuto de Autonomía para Andalucía, lo prescribe en términos similares en su artículo 31, refiriendo el derecho a que los asuntos «sean resueltos en un plazo razonable». Lo ha subrayado con acierto Pérez Monguió (2014: 312-314). 
minado lo establece la Ley de Procedimiento Administrativo: la estatal y «común» Ley 39/2015 y la autonómica Ley 26/2010, de 3 de agosto, de Régimen Jurídico y de Procedimiento de las Administraciones Públicas de Cataluña. ${ }^{6}$ Pero, aun así, no ha de olvidarse el escepticismo doctrinal ante los efectos jurídico-administrativos del incumplimiento de este relevante deber jurídico que tiene la Administración. ${ }^{7}$

\section{Contenido esencial y ámbito de aplicación}

El artículo 21.1 de la Ley de España 39/2015 dispone el contenido primario del deber de resolver en su primer párrafo: "La Administración está obligada a dictar resolución expresa y a notificarla en todos los procedimientos cualquiera que sea su forma de iniciación». El deber legal impuesto a la administración pública consiste, pues, en resolver expresamente el procedimiento administrativo y notificar la resolución a los interesados, sea cual fuere el modo de iniciación (de oficio o a solicitud del interesado: artículo 54 de la Ley 39/2015). Ahora bien, la notificación de la resolución dictada ha de efectuarse antes del vencimiento de un plazo establecido normativamente (Ley 39/2015: artículo 21.2). Tres son, pues, los elementos esenciales integrantes del contenido fundamental del deber: resolución administrativa expresa (elemento objetivo), notificación de la resolución (elemento formal) y plazo de su ejecución (elemento temporal).

\section{¿Resolución administrativa del procedimiento administrativo?}

La ley exige dictar la «resolución», esto es, el acto administrativo que resuelve y termina el procedimiento administrativo (artículo 84.1 de la Ley 39/2015); el acto administrativo expreso formalizado que ha de dictar la administración pública debe ser el acto administrativo finalizador del procedimiento administrativo, y no un acto administrativo de trámite, ${ }^{8}$ sea o no cualificado o asimilado al acto resolutorio a los efectos de su impugnabilidad en vía administrativa (según el artículo 112.1 de la Ley 39/2015).

6. La Ley de la Comunidad Autónoma de Cataluña 26/2010 así lo establece en su artículo 22.1: «El derecho de los ciudadanos a una buena administración incluye: [...] d) El derecho a obtener una resolución expresa y a que se les notifique dentro del plazo legalmente establecido [...]».

7. En particular, tanto la Ley 30/1992 como la Ley 39/2015 no prevén efectivos y adecuados mecanismos de protección (véase Aguado i Cudolà, 2012: 337, especialmente) o de ejecución forzosa (Alonso Ibáñez, 2012: 190-191) ante el incumplimiento de la «obligación» de resolver, más allá de los efectos del silencio administrativo o la caducidad.

8. Esto no significa que todos los actos de trámite no precisen de un previo y específico «procedimiento administrativo» y, por tanto, de una «resolución» que conforme el contenido del acto de trámite. Algunos lo precisan; pero no es un procedimiento administrativo en sentido propio, no es el procedimiento administrativo común, sino uno mini y sumario, instrumental y secundario del auténtico procedimiento administrativo en el que se inserta y se justifica plenamente; en suma, es un procedimiento administrativo de trámite que debe «resolverse» con el debido acto de trámite. Y por ello, la propia Ley 39/2015 los contempla como «trámites» del procedimiento administrativo común: las medidas provisionales que deben «resolverse en plazo» (artículo 56), la emisión de informes o dictámenes en plazo (artículos 80 y 81). 
Ahora bien, la Ley 39/2015 contempla dos modalidades de «resoluciones administrativas», dos clases de actos administrativos terminadores del procedimiento administrativo. La primera es la resolución administrativa en sentido propio o stricto sensu, el auténtico acto administrativo que no solo finaliza el procedimiento, sino que, además, lo resuelve. Esta parece ser la resolución administrativa expresa que demanda el artículo 21.1, es decir, la resolución que contiene la «decisión» administrativa - «que será motivada en los casos a que se refiere el artículo 35» (artículo 88.3)—, motivación que, por cierto, podrá estar integrada por informes o dictámenes «cuando se incorporen» al texto de la propia resolución (artículo 88.6) y que, por imperativo legal, «decidirá todas las cuestiones planteadas por los interesados y aquellas otras derivadas» del procedimiento así resuelto (artículo 88.1) ${ }^{9}$ y «se dictará electrónicamente» (artículo 88.4). En suma, la resolución expresa exigida en el artículo 21.1 parece ser la resolución administrativa «decisora o resolutoria», la resolución no solo «de forma», sino también «de fondo».

Sin embargo, el segundo párrafo del artículo 21.1 reproduce el segundo párrafo del artículo 42.1 de la Ley 30/1992 que, como es sabido, resulta ser capital para la misma delimitación del contenido esencial de la resolución expresa exigida a la Administración:

En los casos de prescripción, renuncia del derecho, caducidad del procedimiento o desistimiento de la solicitud, así como de desaparición sobrevenida del objeto del procedimiento, la resolución consistirá en la declaración de la circunstancia que concurra en cada caso, con indicación de los hechos producidos y las normas aplicables (artículo 21.1 de la Ley 39/2015; artículo 42.1 de la Ley 30/1992).

De esta forma, la resolución administrativa expresa que deberá dictar la administración pública por imperativo del artículo 21 de la Ley 39/2015 no será siempre la resolución administrativa decisora prevista en el artículo 88, sino una segunda modalidad de resolución administrativa finalizadora del procedimiento, sin mediar la decisión administrativa resolutoria, sino una de las causas legales de terminación anormal del procedimiento tipificadas en el artículo 84 de la misma ley. ${ }^{10}$

Ciertamente, la no mención —en el artículo 84.1- de la debida resolución administrativa expresa declarativa de la terminación del procedimiento por «desistimiento»o por «renuncia al derecho»" se suple con la explícita previsión del segundo párrafo del

9. Lo más característico de la resolución administrativa stricto sensu no es, pues, la decisión administrativa que contiene, puesto que la misma Ley 39/2015 admite ciertos actos de trámite que «deciden directa o indirectamente el fondo del asunto» (artículo 112.1), sino la congruencia con el «fondo del asunto» que explícitamente reclama el artículo 88.1.

10. Tras la reforma de la Ley 30/1992 realizada por la Ley 4/1999, Morillo-Velarde Pérez (2002: 105-106) ya destaca las diferencias entre estas resoluciones anormales y otras también anormales diferenciadas, en especial, entre la resolución declaratoria de la caducidad del procedimiento incoado de oficio y la resolución administrativa tardía posterior al silencio administrativo producido.

11. En cambio, el artículo 84.2 sí refiere inequívocamente la resolución administrativa expresa cuando acontece la terminación del procedimiento «por la imposibilidad material de continuarlo por causas sobrevenidas» (Ley 39/2015), añadiendo incluso que «la resolución que se dicte deberá ser motivada en todo 
artículo 21.1 que, como se aprecia, sí exige dictar resolución expresa cuando el procedimiento administrativo termina por cualquiera de las causas legales de finalización distintas a la resolución decisora del artículo 88. Eso sí, será una resolución administrativa expresa que exclusivamente «consistirá en la declaración de la circunstancia que concurra en cada caso, con indicación de los hechos producidos y las normas aplicables» (artículo 21.1 párrafo segundo de la Ley 39/2015); pero resolución administrativa expresa, al fin y al cabo, atendiendo con ella la observancia del deber legal dispuesto en el artículo 21.1.

Por último, la Administración tiene también el deber legal de resolver expresamente «las solicitudes de reconocimiento de derechos no previstos en el ordenamiento jurídico o manifiestamente carentes de fundamento» (artículo 88.5 de la Ley 39/2015). Cierto es que este precepto solo requiere de la Administración un acuerdo de inadmisión de esa «extraordinaria» solicitud, y no una resolución administrativa, estimatoria o desestimatoria de la solicitud formulada. La Administración no parece, pues, estar obligada a resolver el fondo de la solicitud «infundada», esto es, no está obligada a dictar una auténtica resolución administrativa expresa, sino que solo debe dictar un sui generis acto administrativo de «inadmisión», que no puede ser calificado en modo alguno como «inadmisión a trámite». Porque estos acuerdos de inadmisión no son resoluciones administrativas en la concepción estricta dispuesta en el artículo 88, y tampoco son meros actos de trámite, sino que son actos de trámite cualificados; es más, son actos muy cualificados y singulares, constitutivos de la modalidad de acto de trámite más próxima o asimilada a la resolución administrativa, pues no «determinan la imposibilidad de continuar el procedimiento, producen indefensión o perjuicio irreparable a derechos e intereses legítimos» (artículo 112.1 de la Ley 39/2015), sino que «deciden directa o indirectamente el fondo del asunto» (artículo 112.1). Son, pues, unos especialísimos acuerdos administrativos de «inadmisión», auténticos actos administrativos finalizadores del procedimiento, lo que justifica su previsión explícita en el artículo 88, precepto este que, no se olvide, regula el «contenido» de la resolución.

Son, en suma, resoluciones administrativas expresas que ponen fin a los procedimientos iniciados mediante esas «solicitudes», que la resuelven y deciden motivadamente, porque deben expresar la fundamentación de ese no reconocimiento jurídico-administrativo del derecho instado o de la manifiesta carencia de fundamentación jurídico-administrativa de la pretensión; ${ }^{12}$ suficiente motivación, por tanto, ha de cons-

caso»; y también el artículo 84.1 implícitamente contempla la resolución administrativa de la terminación del procedimiento por caducidad al referirse a la «declaración de caducidad».

12. Porque, como acertadamente subrayara (Cantero Martínez, 2007: 1518), «la determinación misma de si se tiene o no derecho o de si la petición carece o no de fundamento supone en sí misma una auténtica decisión sobre el fondo del asunto y que, por ello mismo, debiera quedar oportunamente reflejada en la motivación de la resolución que se adopte declarando inadmisible la petición efectuada». No debe extrañar, pues, que la doctrina y la jurisprudencia admitan este acto de inadmisión «con carácter muy restrictivo para evitar que la Administración pueda rechazar directamente y sin más trámites solicitudes cuya viabilidad ofrezca dudas». 
tar en estos acuerdos de inadmisión, aunque, eso sí, sin requerirse en estos actos resolutorios un pronunciamiento administrativo congruente con las pretensiones de los solicitantes. Por ello, el legislador termina el precepto con la remisión al régimen jurídico-constitucional del derecho fundamental de petición (artículo 29 de la Constitución Española, 1978), y admite así implícitamente un régimen especial excluido del ámbito de aplicación del artículo 21 de la Ley 39/2015, aunque no del deber legal — ¿constitucional? - de los poderes públicos de resolver expresamente los procedimientos ${ }^{13}$ que, por otra parte, confirma la innecesariedad de la reminiscencia histórica — propia del proceso civil y de las resoluciones judiciales - contenida en el apartado inicial del artículo 88.5 de la misma ley. ${ }^{14}$

La Ley 39/2015 prescribe, en su artículo 21.1, que «la Administración está obligada a dictar resolución expresa y a notificarla en todos los procedimientos»; esto es, el deber legal que establece la ley impone la resolución expresa de los procedimientos administrativos. El presupuesto ineludible del deber legal de resolver lo constituye, sin duda alguna, el procedimiento administrativo; la resolución administrativa expresa que debe dictar la Administración requiere, por tanto, el previo procedimiento administrativo al que pone fin. Se excluye así del deber legal de resolver toda actividad administrativa no procedimentalizada (en especial, la actividad administrativa material de ejecución ${ }^{15}$ o actividad administrativa técnica y la coacción administrativa directa o inmediata, así como todo ejercicio de potestades administrativas que, por su propia naturaleza y funcionalidad y por así preverse en el ordenamiento administrativo, no precisa del previo procedimiento administrativo la actividad administrativa de inspección, en

13. La Ley Orgánica 4/2001, de 12 de noviembre, reguladora del Derecho de Petición, impone el deber de «contestar» expresamente la petición (y notificar la resolución en plazo) en el artículo 11 de la Ley Orgánica de España 4/2001: «1. Una vez admitida a trámite una petición, la autoridad u órgano competente vendrán obligados a contestar y a notificar la contestación en el plazo máximo de tres meses a contar desde la fecha de su presentación [...]. 3. La contestación recogerá, al menos, los términos en los que la petición ha sido tomada en consideración por parte de la autoridad u órgano competente e incorporará las razones y motivos por los que se acuerda acceder a la petición o no hacerlo [...]». Y también prescribe el deber de dictar acuerdo expreso de inadmisibilidad, motivado en el artículo 9 de la Ley Orgánica de España 4/2001: «1. La declaración de inadmisibilidad será siempre motivada y deberá acordarse y notificarse al peticionario en los cuarenta y cinco días hábiles siguientes al de presentación del escrito de petición [...]». Se confirma así la autonomía conceptual e institucional del deber legal de resolver respecto de sus típicos efectos jurídicoadministrativos (silencio y caducidad) por incumplimiento. En todo caso, existiendo esta regulación específica y especial del deber de resolver el ejercicio del derecho fundamental de petición, no resulta coherente su previsión en el artículo 24 de la Ley 39/2015, que lo tipifica expresamente como supuesto de silencio administrativo negativo: «1. En los procedimientos iniciados a solicitud del interesado [...] El silencio tendrá efecto desestimatorio en los procedimientos relativos al ejercicio del derecho de petición, a que se refiere el artículo 29 de la Constitución [...]».

14. «En ningún caso podrá la Administración abstenerse de resolver so pretexto de silencio, oscuridad o insuficiencia de los preceptos legales aplicables al caso [...]» (artículo 88.5 de la Ley 39/2015).

15. Véase, por ejemplo, la Sentencia del Tribunal Superior de España, de 28 de febrero de 2007 , criticada por buena parte de la doctrina. Véase, por todos, más recientemente, Aguado i Cudolà, 2012: 375-376. 
principio) ${ }^{16}$ Sin embargo, el último párrafo del artículo 21.1. ya mencionado excluye del ámbito de aplicación del deber legal de resolver a ciertos procedimientos administrativos: «Se exceptúan de la obligación a que se refiere el párrafo primero, los supuestos de terminación del procedimiento por pacto o convenio, así como los procedimientos relativos al ejercicio de derechos sometidos únicamente al deber de declaración responsable o comunicación a la Administración» (artículo 21.1 párrafo final de la Ley 39/2015). Y ambos supuestos de exclusión presentan características muy distintas que, en su caso, pudieran justificar su explícita exención del deber dispuesto en el artículo 21.1.

El primero de ellos alude a la terminación convencional del procedimiento administrativo prevista en el artículo 86 de la Ley 39/2015, y más exactamente a la terminación convencional stricto sensu, a los actos administrativos convencionales finalizadores del procedimiento. Estamos, pues, ante un procedimiento administrativo que termina mediante un acuerdo administrativo bilateral y no mediante una resolución administrativa dictada unilateralmente por la Administración. Pero es un auténtico procedimiento administrativo, un procedimiento que también debe la Administración resolver expresamente (y con un contenido mínimo preceptivo: el artículo 86.2 de la Ley 39/2015) -aunque, cierto es, no por un acto administrativo unilateral-y notificar a los interesados (artículo 40.1) y que también tiene un plazo máximo de resolución (y notificación).

La singularidad de estos procedimientos administrativos convencionales en lo referente al deber legal de resolver es, principalmente, el régimen especial del plazo máximo y sus efectos que su normativa específica ha de establecer en virtud de lo dispuesto en el artículo 86.1 de la Ley 39/2015; en modo alguno la Ley 39/2015 los excluye del deber legar de resolver y de sus principios institucionales, sino tan solo del régimen general

16. Rebollo Puig, 2013: 29 y ss. ha rechazado explícitamente que la actividad administrativa inspectora esté procedimentalizada en nuestro derecho administrativo y, específicamente, se prevea un plazo máximo de duración: «Pero lo que interesa señalar con carácter general es que las actuaciones inspectoras [...] no están sometidas necesariamente a las reglas y principios del procedimiento administrativo propiamente dicho, en especial el principio de contradicción, ni los administrados tienen los derechos que sí les asisten en él [...]. En general, tampoco la inspección está sometida a las reglas sobre duración máxima de los procedimientos ni, en general, esto tendría sentido porque de ordinario cada actuación inspectora es una unidad en sí misma [...]. Esos requerimientos, producidos incluso verbalmente, tampoco son actos de trámite en otro procedimiento, pues no existe aún otro procedimiento en el que insertarlos [...]. Corrobora la no procedimentalización de la inspección [...]». Pero, aun así, al menos ciertas regulaciones especiales de la inspección administrativa sí establecen una procedimentalización de la actividad inspectora (la Ley 58/2003, de 17 de diciembre, General Tributaria (LGT) regula el llamado procedimiento de inspección en los artículos 145 y siguientes), disponiendo incluso un plazo máximo de duración y el deber legal de «resolverlas» expresamente (doce meses en el artículo 150 de la LGT y nueve meses en el artículo 14.2 de la Ley 42/1997, de 14 de noviembre, ordenadora de la Inspección de Trabajo y Seguridad Social) e, incluso, su caducidad por vencimiento de ese plazo sin «resolución» (artículo 8.2 del Real Decreto de España 928/1998, de 14 de mayo, por el que se aprueba el reglamento general sobre procedimientos para la imposición de sanciones por infracciones de orden social y para los expedientes liquidatorios de cuotas de la Seguridad Social). 
establecido en los artículos 21 y siguientes. Así lo confirma la misma ley cuando dispone el régimen especial de la terminación convencional del procedimiento de responsabilidad patrimonial de la Administración en su artículo 91.3, prescribiendo no solo el plazo máximo de duración, sino también el deber de dictar y formalizar el acuerdo finalizador (resolución administrativa bilateral expresa) dentro de ese plazo y los efectos de la infracción del deber de resolver en plazo: «Transcurridos seis meses desde que se inició el procedimiento sin que haya recaído y se notifique resolución expresa o, en su caso, se haya formalizado el acuerdo, podrá entenderse que la resolución es contraria a la indemnización del particular» (artículo 91.3).

El segundo supuesto de exclusión establecido en el citado párrafo del artículo 21.1 presenta aún mayor interés, porque remite al régimen singular «de tramitación» de las llamadas declaraciones responsables y comunicaciones previas tipificadas genéricamente en el artículo 6o de la Ley 39/2015. En efecto, «los procedimientos relativos al ejercicio de derechos sometidos únicamente al deber de declaración responsable o comunicación a la Administración» (artículo 21.1, último párrafo) no tienen dispuesto en la Ley 39/2015 un plazo máximo de resolución (y notificación), puesto que el mismo fundamento y la finalidad esencial de su incorporación al ordenamiento administrativo procedimental común así lo impide; si el artículo 69 de dicha ley, acorde a esos fundamentos y finalidades institucionales, no establece una preceptiva «resolución administrativa» finalizadora del procedimiento administrativo iniciado por el interesado con la presentación de la declaración responsable o la comunicación previa, está justificada la ausencia de plazo máximo alguno de resolución y notificación. Por ello, la expresa tipificación como supuesto de exclusión del ámbito objetivo del deber legal de resolver dispuesto en el artículo 21.1 se explica plenamente. ${ }^{17}$

17. Obsérvese, no obstante, que cuando el interesado pretende con la declaración responsable «obtener el reconocimiento de un derecho o facultad» (Ley 39/2015: artículo 69.1) y la normativa específica establezca un plazo «de tramitación» (de comprobación de los requisitos declarados, de preaviso al inicio del ejercicio del derecho/facultad cuyo reconocimiento pretende), se prevé en su artículo 69.4 una resolución administrativa prohibitiva ante «la inexactitud, falsedad u omisión, de carácter esencial, de cualquier dato o información que se incorpore a una declaración responsable» o la no presentación de la documentación «que sea en su caso requerida para acreditar el cumplimiento de lo declarado»; así la prescribe: «[...] la resolución de la administración pública que declare tales circunstancias» y que "podrá determinar la obligación del interesado de restituir la situación jurídica al momento previo al reconocimiento [...] del derecho [...], así como la imposibilidad de instar un nuevo procedimiento con el mismo objeto durante un período de tiempo determinado por la ley, todo ello conforme a los términos establecidos en las normas sectoriales de aplicación» (Ley 39/2015: artículo 69.4). Por tanto, en estos procedimientos iniciados por declaración responsable podría postularse un cierto deber legal de resolver expresamente «en plazo» - eso sí, una resolución administrativa expresa desestimatoria de la pretensión del declarante- y el efecto del «silencio administrativo positivo» o acto administrativo presunto estimatorio de la pretensión formulada en la declaración responsable por el vencimiento de ese plazo sin haberse dictado y notificado la «resolución expresa» desestimatoria del reconocimiento del derecho instado. 


\section{Notificación de la resolución expresa}

El contenido esencial del deber legal de la Administración dispuesto en el artículo 21 de la Ley 39/2015 no es únicamente dictar la resolución administrativa expresa del procedimiento sino, además, notificarla. Así lo dispone explícitamente en su primer apartado: «1. La Administración está obligada a dictar resolución expresa y a notificarla [...]» (artículo 21.1), lo que se confirma posteriormente en el apartado 2 y en el artículo 22.1, que se examinará más adelante (artículo 22.1: «El transcurso del plazo máximo legal para resolver un procedimiento $y$ notificar la resolución [...]»). No basta, pues, que la Administración resuelva expresamente el procedimiento, sino que es preciso también que se lo comunique al interesado; no basta, por tanto, con la emisión del acto administrativo resolutorio finalizador del procedimiento, sino que además se requiere un segundo acto administrativo: el acto de la notificación administrativa, que debe practicarse de conformidad con lo dispuesto en los artículos 40 y siguientes.

De esta forma, la notificación administrativa no es tan solo un requisito de eficacia de la resolución administrativa dictada en plazo, sino que implícitamente se convierte en un requisito de validez ex post de la congruente resolución expresa no tardía dictada por la Administración, ${ }^{18}$ por cuanto la ausencia de su notificación produce la terminación anormal del procedimiento administrativo por silencio o por caducidad y, en este sentido, la invalidez per se de la resolución expresa dictada pero no notificada, salvo en el supuesto en que la resolución administrativa tardía sea estimatoria de la solicitud y el efecto atribuido por la ley sea el silencio administrativo positivo. ${ }^{19}$ Ninguna novedad, pues, respecto del régimen establecido en la Ley 30/1992 tras la reforma realizada por la Ley $4 / 1999$, de 13 de enero. ${ }^{20}$

18. Con la Ley 30/1992, Parejo Alfonso (1999: 124-125) ya se pronunciaba en la misma línea, con más acierto: «[...] Por tanto, ha de concluirse que la notificación en plazo de las resoluciones de que se viene hablando tiene hoy la condición, si no de requisito (lo que resultaría excesivo, por asistemático, teniendo en cuenta la naturaleza de la notificación, que habría de seguir jugando con un alcance totalmente distinto y desde luego menor respecto de cualesquiera otros actos administrativos), sí al menos de condición legal resolutoria de la validez. Esta consideración es plausible, en la medida en que la no notificación en tiempo representa la infracción de una norma legal (impositiva de la pertinente obligación), que vicia sobrevenidamente la resolución, es decir, que la hace inválida por no levantamiento de la carga establecida por el legislador para el perfeccionamiento definitivo de la resolución expresa [...]».

19. En este caso la resolución expresa tardía estimatoria no se invalidaría con el acto presunto estimatorio, al tener la estimación por silencio administrativo «la consideración de acto administrativo finalizador del procedimiento» (Ley 39/2015: artículo 24.2) y deber ser la resolución expresa posterior a la producción del acto presunto estimatorio "confirmatoria del mismo» (artículo 24.3 letra b) de la Ley 39/2015).

20. Con esta reforma, el artículo 42.1 de la Ley 30/1992 amplió así «considerablemente los deberes de la Administración», como entonces destacara Parejo Alfonso (1999: 121-122): «Esta innovación (la inclusión de la notificación-publicación en el contenido de la obligación legal a cumplir en tiempo hábil al efecto), en la que - como se verá - insiste una y otra vez el legislador de la reforma, no es baladí: agrava considerablemente el cumplimiento de la Administración. Pues esta no tiene ya todo el tiempo del plazo legal máximo fijado por la norma ordenadora del procedimiento para dictar la resolución finalizadora. Ha de producir esta con la anticipación suficiente como para que la notificación pueda tener lugar aun efectivamente antes 
Por tanto, el deber de resolver y notificar la resolución que dispone el artículo 21 de la Ley 39/2015 se cumple por la Administración cuando la notifica en plazo con los requisitos formales establecidos en su artículo 40.2; esto es, cuando la resolución administrativa se notifica dentro del plazo de diez días desde que se ha dictado y la notificación contiene el texto íntegro de la resolución, la indicación de si la resolución pone fin o no a la vía administrativa, la expresión de los recursos que procedan, los órganos ante los que hubieran de presentarse y los plazos de interposición.

Ahora bien, a semejanza de su antecedente en el artículo 58.4 de la Ley 30/1992, el artículo 40.4 de la Ley 39/2015 establece un supuesto de resolución expresa no notificada en plazo debidamente y que, sin embargo, sí surte los efectos de la «notificación» requerida por el artículo 21 a la Administración como elemento del deber legal de resolver:

Sin perjuicio de lo establecido en el apartado anterior, y a los solos efectos de entender cumplida la obligación de notificar dentro del plazo máximo de duración de los procedimientos, será suficiente la notificación que contenga, cuando menos, el texto íntegro de la resolución, así como el intento de notificación debidamente acreditado (artículo 40.4 de la Ley 39/2015).

De esta forma, «se le va a dar relevancia a la diligencia que ha puesto la Administración en comunicar al interesado el acto administrativo» (Cantero Martínez, 2007: 1.511), aunque la notificación no se haya practicado efectivamente y solo se haya intentado. Eso sí, es preciso que haya tenido lugar esa notificación administrativa «en grado de tentativa» dentro del plazo máximo de resolución (y notificación de la resolución) o, en términos literales establecidos en la norma, que se haya realizado «el intento de notificación» y este se encuentre «debidamente acreditado». Pero ¿qué entiende el legislador del 2015 por «intento de notificación» a estos efectos? ${ }^{21}$ Resulta obligatorio, por tanto,

de la finalización del referido plazo...». En similar sentido se pronuncia Cantero Martínez (2007: 1.511), explicándolo así: «[...] Quiere ello decir que la Administración podría encontrarse con una situación ciertamente problemática en los supuestos de resoluciones tardías, esto es, en los casos en que, aun habiendo cumplido con su primera obligación de resolver expresamente dentro del plazo, no le hubiera dado tiempo a cumplir con la segunda de sus obligaciones, esto es, con la de notificar o comunicar personalmente al interesado la resolución administrativa [...]. La notificación se convierte así en una fase esencial en la medida en que de ella va a depender directamente que produzcan o no sus efectos las instituciones de la caducidad y del silencio administrativo [...]».

21. Los problemas interpretativos de la expresión «intento de notificación debidamente acreditado» ya se señalan inmediatamente por la doctrina (véase, por todos, Cantero Martínez, 2007: 1514-1515) y posteriormente por la jurisprudencia. Así, en especial, la Sentencia del Tribunal Superior de España, de 17 noviembre de 2003) interpreta - en relación con la notificación más habitual, la que se efectúa por medio de correo certificado con acuse de recibo- que el «intento de notificación debidamente acreditado» requiere haber realizado el doble intento infructuoso de notificación y también que la Administración reciba la devolución del envío de la notificación, acreditándose así el intento de notificación realizado. Pero la más reciente (Sentencia del Tribunal Superior de España, de 3 de diciembre de 2013) rectifica la doctrina formulada por dicha sentencia de 2003, declarando que para que surta efectos el artículo 58.4 de la Ley 30/1992 $-\mathrm{y}$, por tanto, se entienda cumplida la obligación de resolver- basta con que se intente la notificación, sin 
remitirse al régimen de las prácticas de las notificaciones administrativas establecido en los artículos 42 y siguientes de la Ley 39/2015, y diferenciar así entre los intentos de las notificaciones «en papel» y los intentos de notificaciones «electrónicas», pese a la norma común dispuesta en el artículo 41.6.

Finalmente, también el artículo 40.3 de la Ley 39/2015 prevé implícitamente otro supuesto de resolución expresa no notificada debidamente y que produce, entre otros, el efecto de la «notificación» exigida en el deber legal de resolver:

Las notificaciones que, conteniendo el texto íntegro del acto, omitiesen alguno de los demás requisitos previstos en el apartado anterior, surtirán efecto a partir de la fecha en que el interesado realice actuaciones que supongan el conocimiento del contenido y alcance de la resolución o acto objeto de la notificación, o interponga cualquier recurso que proceda.

Aquí no hay intento de notificación o notificación «en grado de tentativa», sino una realizada o ejecutada, aunque defectuosa e inválida, en principio, y posteriormente convalidada y subsanada por la actuación del interesado destinatario; así, el deber de resolver y notificar la resolución en plazo deviene cumplido, y se evita el efecto del silencio o la caducidad del procedimiento.

\section{Resolución expresa y notificación «en plazo»}

La tipificación legal del deber de resolver (y notificar la resolución) establecida en el artículo 21.1 de la Ley 39/2015 no contiene, sorprendentemente, el tercer elemento institucional y esencial: el plazo de resolución/notificación. El artículo 21 continúa difiriendo al segundo apartado su explícita tipificación legal, al referirse al «plazo máximo en el que debe notificarse la resolución expresa [...]» (Ley 39/2015: artículo 21.2). De esta forma, el legislador solo conforma el deber legal de resolver en atención a un plazo máximo de cumplimiento del deber, sin disponer plazo mínimo alguno de resolución que, en su caso, garantizara en cierta medida la finalidad y el contenido debido de la resolución final del procedimiento que prevé, en primer término, el artículo 88 de la Ley $39 / 2015 .^{22}$

que sea necesario que la Administración reciba la devolución del envío o la comunicación fehaciente de que el intento de notificación ha resultado infructuoso; en otras palabras, el Tribunal Superior considera que es suficiente que el intento de notificación se realice dentro del plazo máximo de duración del procedimiento para que se produzcan los efectos «convalidantes» del precepto, aunque la acreditación de esa circunstancia se produzca en un momento posterior, incluso cuando haya vencido el plazo para resolver y notificar; la acreditación del intento de notificación ya no es elemento necesario de intento de notificación que produce los efectos de cumplimiento del deber legal de resolver y notificar en plazo.

22. Es más, la normativa reglamentaria estatal prevé que en un plazo de diez días desde la recepción de la solicitud por el órgano administrativo tramitador se dicte -y se notifique incluso- la resolución administrativa expresa. El Real Decreto 137/2010, de 12 de febrero, sobre los criterios para la emisión de la comunicación a los interesados prevista en el artículo 42.4 de la Ley 30/1992 así lo dispone en su artículo 1: «3. La emisión de la comunicación no será necesaria en los siguientes casos: b) Cuando, dentro del plazo 
El artículo 21.2 impone, pues, un plazo máximo en el que la Administración no solo ha de resolver expresamente el procedimiento sino que, además, debe notificar la resolución, sin perjuicio del régimen especial previsto para las notificaciones intentadas o las defectuosas subsanadas, aún vencido ese plazo máximo, como se ha visto anteriormente.

\section{Los plazos máximos de resolución y notificación}

\section{Determinación normativa}

El artículo 21 de la Ley 39/2015 reserva al ordenamiento jurídico-administrativo la predeterminación de los plazos máximos de resolución y notificación, esto es, el plazo máximo lo establece una norma jurídica - legal o reglamentaria, en los términos que veremos- y no un acto administrativo - general o singular- que dicte la administración pública. La atribución de los efectos previstos en los artículos 24 y 25 de la misma ley (silencio o caducidad) cuando acontece ese vencimiento del plazo sin notificación de la resolución -y su incidencia o afectación en el status jurídico-administrativo del interesado en el procedimiento así finalizado- demanda esa previa reserva normativa del plazo, congruentemente con la vinculación positiva de la Administración al principio de legalidad que, por cierto, también se aprecia en las potestades administrativas ejercitables posteriormente, dictando, en primer lugar, las tardías y debidas resoluciones administrativas.

El plazo máximo lo establece, en concreto, «la norma reguladora del correspondiente procedimiento» (Ley 39/2015: artículo 21.2), sea estatal, autonómica o local, y sea sectorial o general. Pero el mismo artículo establece un límite para la determinación por vía reglamentaria: seis meses ${ }^{23}$ («[...] este plazo no podrá exceder de seis meses salvo que una norma con rango de ley establezca uno mayor o así venga previsto en el Derecho de la Unión Europea»). La Ley 39/2015 prescribe así una reserva de rango normativo, una reserva de ley material - no formal - y de norma comunitaria ${ }^{24}$ para establecer plazos superiores al límite temporal indicado. Nada novedoso respecto de su precedente dispuesto en el artículo 42 de la Ley $30 / 1992$.

Por último, recuérdese el plazo supletorio de tres meses dispuesto para todo procedimiento administrativo cuya regulación -legal o reglamentaria - no haya establecido

establecido para emitir la comunicación a la que se refiere el presente Real Decreto, se dicte y se notifique la resolución expresa correspondiente que ponga fin al procedimiento [...]».

23. La Administración tiene un amplio margen para elegir reglamentariamente la duración de sus procedimientos. Así lo han reconocido algunas sentencias como, por ejemplo, la Sentencia del Tribunal Superior de Castilla-La Mancha, de 31 de octubre de 2003: «[...] es un plazo máximo sujeto a reserva de ley, por lo que a sensu contrario parece claro que reglamentariamente se puede fijar un plazo que no exceda de dicha duración $[\ldots] »$.

24. La posición en el sistema de fuentes del derecho español así lo reclama, conforme a la primacía del ordenamiento comunitario y su efecto directo en el ordenamiento jurídico de cada Estado miembro. 
el plazo máximo de resolución/notificación, plazo supletorio explícitamente contenido en el artículo 21.3 de la Ley 39/2015: «Cuando las normas reguladoras de los procedimientos no fijen el plazo máximo, este será de tres meses»; y también contemplado en el artículo 42.3 de la Ley 30/1992. De esta forma, una vez más, el legislador estatal y común no ha tenido en cuenta la conveniencia de establecer varios plazos supletorios, en atención a la notable pluralidad de plazos máximos tipificados en las normas legales y reglamentarias que debieran servir de referencia, así como en atención a la inefectividad e inutilidad del plazo supletorio de tres meses en no pocos procedimientos administrativos de difícil o imposible duración trimestral.

\section{Cómputo}

El modo de computar el plazo máximo de resolución (y notificación de la resolución) lo establece explícitamente el artículo 21.3, y es una norma común y general de cómputo, que rige para todo plazo máximo de duración procedimental, sea el supletorio de tres meses dispuesto en la Ley 39/2015 o uno inferior o superior dispuesto en la normativa procedimental específica, sea un plazo establecido reglamentariamente o uno tipificado por una norma con valor de ley. Todos los plazos máximos procedimentales se computan aplicando la norma del artículo 21.3, que exclusivamente admite una dualidad en el cómputo en atención a las dos modalidades de iniciación procedimental que establece el artículo 54 (de oficio o a solicitud), según, pues, el procedimiento lo haya iniciado la administración pública o, en cambio, lo haya decidido iniciar el interesado.

Ahora bien, esta dualidad del cómputo solo está presente en el día inicial del plazo (no afecta al día final) en atención, precisamente, a la referida dualidad de iniciación procedimental que admite la Ley 39/2015. El artículo 21.3 se refiere, por tanto, al dies a quo: la fecha en que comienza el plazo máximo normativamente establecido para resolver y notificar el procedimiento; y dicha ley es taxativa al respecto.

En primer lugar, la letra a) del artículo 21.3 prescribe que en los procedimientos iniciados de oficio el plazo máximo procedimental se computa «desde la fecha del acuerdo de iniciación» (Ley 39/2015). El día inicial del plazo es, en consecuencia, el día en que se adopta la decisión administrativa de iniciar el procedimiento administrativo, sea cual sea la fecha en que el interesado conoce el acuerdo de iniciación; en efecto, en particular es irrelevante a estos efectos la fecha de la notificación administrativa, ${ }^{25}$ si ha sido una notificación válida o defectuosa, si se ha producido una notificación consumada, fracasada o intentada, etcétera. En todo caso, el plazo comienza con la fecha del acuerdo de iniciación dictado por el órgano administrativo competente al que se refiere el artículo 58 de la Ley 39/2015, que es así el único órgano cuya voluntad determina el inicio del plazo de duración procedimental y, por consiguiente, el comienzo del plazo cuyo ven-

25. La jurisprudencia así lo ha reiterado en numerosas ocasiones como, por ejemplo, en la Sentencia del Tribunal Superior de España, de 15 de octubre de 2001 o la Sentencia del Tribunal Superior de Justicia de Canarias, de 17 de marzo de 2005. 
cimiento sin resolución produce ex lege los relevantes efectos jurídico-administrativos ya anunciados.

Por ello, ninguno de los actos administrativos previos al acuerdo de iniciación afecta al cómputo del plazo máximo de resolución/notificación del procedimiento, sean los trámites administrativos -o, en su caso, procedimiento no formalizado- que conforman los antecedentes inmediatos y justificativos de la misma incoación (la llamada «información o actuaciones previas» regulada en el artículo 55), ${ }^{26}$ sea el acto administrativo - en ocasiones parcialmente anticipatorio de la resolución final del procedimiento aún no incoado- que también determina el inicio de un sumario plazo de ejercicio de la potestad incoadora del procedimiento administrativo así «anticipado» (las medidas provisionalísimas previstas en el artículo 56.2) o, finalmente, sea cualquiera de los actos administrativos (o del administrado, incluso) que el artículo 58 califica implícita e indirectamente de causa misma del acuerdo de incoación. ${ }^{27}$

En segundo lugar, la letra b) del artículo 21.3 dispone que en los procedimientos iniciados a solicitud del interesado el plazo máximo de resolución/notificación del procedimiento se computa «desde la fecha en que la solicitud haya tenido entrada en el registro electrónico de la Administración u organismo competente para su tramitación» (Ley 39/2015). De esta forma, la fecha de presentación de la solicitud de iniciación del procedimiento en cualquiera de los registros administrativos tipificados en el artículo 16.4 de la misma ley no es la determinante en el cómputo del plazo máximo de duración procedimental. El acto jurídico-administrativo iniciador del procedimiento es, en efecto, la «solicitud de iniciación» precisamente, y como tal produce el relevante efecto jurídico de evitar la prescripción o la caducidad de la acción administrativa del interesado-solicitante; ${ }^{28}$ pero este acto del administrado-interesado no inicia el plazo máximo de resolución/notificación del procedimiento.

La fecha de iniciación del procedimiento no es la fecha del registro presencial de

26. La jurisprudencia es clarificadora desde hace tiempo. Así, por ejemplo, la Sentencia de la Audiencia Nacional de España, de 5 de mayo de 2004, indica que, a efectos del cómputo del plazo de duración procedimental, no computan dentro del plazo de caducidad las «actuaciones previas» a la iniciación del procedimiento para el ejercicio de la potestad sancionadora, pues solo pretenden determinar, con carácter preliminar, si concurren las circunstancias que justifiquen la iniciación del procedimiento.

27. Ni siquiera la orden administrativa de incoar el procedimiento, dictada por el órgano superior jerárquico del competente para incoarlo, «anticipa» el día inicial si el órgano competente la obedece y dicta el acuerdo de iniciación; este acuerdo de incoación dictado en cumplimiento de la orden jerárquica de incoación no tiene en modo alguno eficacia retroactiva y remitida a la fecha de la orden emitida, porque la Ley 39/2015 no lo ha dispuesto y, en cambio, sí ha establecido, sin excepciones o modulaciones, el dies a quo en la fecha del acuerdo de incoación. Y menos aún la fecha en que se haya formulado por otro órgano no superior la "petición razonada» de incoación o por un administrado la denuncia de hechos determinantes de la incoación de oficio (Sentencia del Tribunal Superior de Justicia del País Vasco, de 14 de febrero de 2005), repercute en el día inicial del plazo máximo de duración procedimental.

28. Por ejemplo, la solicitud de iniciación del procedimiento de responsabilidad patrimonial de la Administración impide la prescripción de la acción administrativa indemnizatoria («derecho a reclamar»), en los términos establecidos en el artículo 67.1 de la Ley 39/2015. 
la solicitud en papel en los registros administrativos presenciales habilitados al efecto en las letras b) a e) del artículo 16.4 de la Ley $39 / 2015{ }^{29} \mathrm{Y}$ tampoco es la fecha de presentación de la solicitud en los registros administrativos electrónicos habilitados como registros administrativos de entrada en la letra a) del mismo artículo, incluyendo el «registro electrónico de la Administración u Organismo al que se dirijan» (Ley 39/2015: artículo 16.4 letra b)). El día inicial no es el día inicial del interesado, sino el día inicial de la Administración; y no necesariamente la Administración receptora ab initio de la solicitud, sino la administración pública competente para tramitar y resolver el procedimiento administrativo así iniciado. ${ }^{30}$ Eso sí, el artículo 21.4 de la Ley 39/2015, a semejanza de su antecedente en el artículo 42 de la Ley 30/1992, impone a la Administración tramitadora del procedimiento el deber legal de informar al solicitante interesado de la fecha de entrada o recepción de la solicitud iniciadora del procedimiento «en el registro electrónico de la Administración u organismo competente para su tramitación» (Ley 39/2015: artículo 21.4).

\section{Publicación y notificación}

El citado artículo 21.4 establece dos específicos deberes administrativos informativos, que son adicionales y complementarios del deber de resolver stricto sensu.

\section{Publicación}

El primer deber legal ha de efectuarse previamente a la iniciación de los procedimientos administrativos y con independencia de los procedimientos que se inicien y del momento en el que se inicien, por cuanto se trata de un deber general de publicidad activa. Ciertamente, dada la pluralidad de plazos máximos de resolución de los procedimientos que normativamente -por vía reglamentaria incluso-pueden establecerse en virtud de lo dispuesto en el artículo 21.2, no ha de extrañar que la Ley 39/2015 —como ya lo hiciera la Ley 30/1992- exija a todas las administraciones públicas:

publicar y mantener actualizadas en el portal web, a efectos informativos, las relacio-

29. Presentación que no es «definitiva», sino meramente convertible en electrónica conforme dispone el artículo 16.5: «Los documentos presentados de manera presencial ante las administraciones públicas, deberán ser digitalizados, de acuerdo con lo previsto en el artículo 27 y demás normativa aplicable, por la oficina de asistencia en materia de registros en la que hayan sido presentados para su incorporación al expediente administrativo electrónico, devolviéndose los originales al interesado, sin perjuicio de aquellos supuestos en que la norma determine la custodia por la Administración de los documentos presentados o resulte obligatoria la presentación de objetos o de documentos en un soporte específico no susceptibles de digitalización [...]» (Ley 39/2015: artículo 16.5).

30. Conforme a lo dispuesto en el artículo 16.1, el registro administrativo válido a esos efectos será bien el Registro Electrónico General que debe tener cada Administración o bien, en el caso de que se haya creado, el registro electrónico del organismo público instrumental destinatario competente para tramitar el procedimiento. 
nes de procedimientos de su competencia, con indicación de los plazos máximos de duración de los mismos, así como de los efectos que produzca el silencio administrativo (artículo 21.4 de la Ley 39/2015).

Una vez más, el legislador del 2015 no ha aportado mejora alguna en la regulación de esta obligación legal informativa en los portales web administrativos, pese al creciente uso de estos canales informativos por parte de los ciudadanos y pese al leitmotiv («electrónica») que preside transversalmente la misma Ley 39/2015. Primero, porque literalmente solo se refiere al silencio administrativo, sin mencionar el nomen iuris del efecto característico y propio de la superación del plazo máximo de los procedimientos administrativos incoados de oficio en los que la Administración ejercite "potestades sancionadoras», "de intervención» o «susceptibles de producir efectos desfavorables o de gravamen»: la caducidad (artículo 25.1 letra b) de la Ley 39/2015). Cierto es que podría interpretarse el «silencio administrativo» que refiere el artículo 21.4 de la misma ley en un sentido impropio, esto es, como inactividad administrativa de resolver cualquier procedimiento administrativo en el plazo y la forma debida y, por tanto, incluir así también a los procedimientos incoados de oficio "desfavorables»; pero bien poco esfuerzo hubiera tenido el legislador en subsanar la defectuosa previsión de su antecedente del artículo 42.4 de la Ley 30/1992 que, sin embargo, ha reproducido. ${ }^{31}$

Segundo, porque la misma finalidad que preside el deber de publicidad activa establecido en el precepto, y el mismo reconocimiento del derecho del interesado tipificado en la letra f) del artículo 53, ${ }^{32}$ demanda ampliar el contenido informativo exigible a la Administración en un instrumento tan «general» y común como es el portal web. ${ }^{33}$ En primer término, atendiendo al mismo artículo 21 y a las, en su caso, previsiones en normativas sectoriales o procedimentales, debería también informarse de las reglas

31. Por cierto, el mismo «defecto» se aprecia también en la tipificación de los derechos informativos del interesado que establece la Ley 39/2015 en su artículo 53.1 letra a): «A conocer [...]; el sentido del silencio administrativo que corresponda, en caso de que la Administración no dicte ni notifique resolución expresa en plazo $[\ldots] »$. Pero no ha de extrañar si se recuerda que la principal normativa reglamentaria específica del deber de comunicar al interesado esa información (Real Decreto de España 137/2010, de 12 de febrero de 2010) tampoco exige que en la notificación del acuerdo de incoación de oficio del procedimiento conste el efecto de la caducidad que se establece para los procedimientos susceptibles de producir resoluciones de gravamen, y, en cambio, sí se menciona el efecto del silencio administrativo previsto para los procedimientos susceptibles de resoluciones favorables; su artículo 4, referente a los procedimientos iniciados de oficio, así lo prescribe: «2. En los supuestos a los que se refiere el artículo 44.1 de la Ley 30/1992, de 26 de noviembre, de Régimen Jurídico de las Administraciones Públicas y del Procedimiento Administrativo Común, la notificación o publicación prevista en el presente apartado hará mención de los efectos desestimatorios del silencio administrativo» (Real Decreto de España 137/2010: artículo 4).

32. «A obtener información y orientación acerca de los requisitos jurídicos o técnicos que las disposiciones vigentes impongan a los proyectos, actuaciones o solicitudes que se propongan realizar» (artículo 53 letra f) de la Ley 39/2015).

33. Y ello pese a su «carácter meramente informativo» que declara la ley y admite la jurisprudencia, sin vinculación para la Administración en el supuesto de que pueda producirse a posteriori alguna discrepancia (Sentencia de la Audiencia Nacional de España, de 18 de julio de 2001). 
esenciales del cómputo del plazo publicado (día inicial, día final, cómputo de plazo por meses...).Y en segundo lugar, si es obligado a publicar todos los procedimientos de «su competencia», deberían publicarse en la información referente a cada procedimiento las causas legales de suspensión del cómputo del plazo que les resulten aplicables y sus cómputos respectivos, conforme prescribe el artículo 22, al que más adelante nos referiremos, máxime atendiendo a las novedades introducidas por el legislador del 2015 y a la habitualidad que presenta la aplicación de ciertas causas legales de suspensión procedimental.

\section{Notificación}

El segundo deber informativo que establece el artículo 21.4 sí requiere la iniciación de un procedimiento administrativo determinado, porque se trata de una obligación directamente instrumental de la concreta comprobación del deber legal de resolver en cada procedimiento comenzado, la observancia y supervisión que corresponde realizar al interesado en el procedimiento. No basta, pues, con que la administración pública, mediante la publicación en su web principalmente, informe - previa y genéricamente a todos los administrados - de los plazos máximos de duración de sus procedimientos y de los efectos legales previstos ante su incumplimiento. La Ley 39/2015 exige, además, una información administrativa específica e individual, y, por tanto, una información suministrada a cada interesado cuando, precisamente, sea interesado en el procedimiento, y la Administración deba, consecuentemente, informarle mediante la práctica de la notificación administrativa -0 , en su caso, mediante la publicación- $-{ }^{34}$ de un mero acto administrativo de trámite y de carácter informativo.

Ahora bien, la forma de notificarse esa preceptiva información difiere según la modalidad de iniciación procedimental. En los procedimientos administrativos incoados de oficio, el acto de trámite informativo se integra en el mismo acto administrativo notificador y forma parte del propio contenido de la notificación administrativa del primer acto administrativo procedimental -es, además, el acto iniciador del procedimiento-que es el «acuerdo administrativo de iniciación». La Administración, cuando incoa de oficio el procedimiento y notifica la incoación, debe notificar también la referida información al interesado.

En cambio, en los procedimientos iniciados a solicitud del interesado el acto de trámite informativo ${ }^{35}$ sí constituye un autónomo acto administrativo de trámite stricto sen$s u$, puesto que no se integra en notificación administrativa alguna, sino que en sí mismo es un relevante acto administrativo de trámite -el primero del procedimiento- que se

34. Así se prevé expresamente cuando sean procedimientos incoados de oficio; y se realizarán en los supuestos en los que se prevé la publicación -adicional o sustitutiva- de los actos administrativos (Ley 39/2015: artículos 44 y 45.1).

35. La relevancia de este deber informativo en estos procedimientos ha sido subrayada reiteradamente por la doctrina como expresión de «nuevos» principios de colaboración en las relaciones Administraciónadministrados. Véase, por todos, (Entrena Cuesta, 2002: 159) y (Fernández Valverde, 2000: 91). 
debe notificar al interesado en el plazo máximo de «los diez días siguientes ${ }^{36}$ a la recepción de la solicitud iniciadora del procedimiento ${ }^{37}$ en el registro electrónico de la Administración u organismo competente para su tramitación» (Ley 39/2015: artículo 21.4). ${ }^{38}$

La Ley 39/2015, no obstante, no contempla previsión alguna específica para el incumplimiento de este deber informativo singular e individualizado al interesado ${ }^{39}$ por lo que la omisión de esa preceptiva comunicación administrativa, en tanto causase indefensión al interesado afectado, podría constituir un vicio de anulabilidad del procedimiento y la resolución final expresa, en virtud del artículo 48.2 de la Ley 39/2015. Por el contrario, el mero retraso en la notificación administrativa informativa -esto es, la comunicación tardía y extemporánea notificada, bien con posterioridad a la notificación del acuerdo de incoación de oficio, bien con posterioridad al vencimiento del plazo de diez días desde la recepción de la solicitud en el registro electrónico de la Administración tramitadora - solo podrá constituir una mera irregularidad administrativa invalidante al no ser contraria a la naturaleza del plazo indicado como requiere el artículo 48.3 de la Ley 39/2015 para poder apreciar el efecto invalidante de la actuación administrativa extemporánea.

36. El Real Decreto de España 137/2010, de 12 de febrero de 2010 dispone en su artículo 1.4 un plazo incluso inferior para ciertos procedimientos iniciados a instancia de parte: «En los procedimientos iniciados a través de la ventanilla única a que hace referencia el artículo 18 de la Ley 17/2009, de 23 de noviembre, sobre el libre acceso a las actividades de servicios y su ejercicio, la comunicación deberá realizarse en un plazo máximo de cinco días».

37. Recuérdese que el presupuesto legal de este deber informativo -la emisión y notificación de este específico acto administrativo de comunicación - lo constituye la solicitud de iniciación del procedimiento administrativo prevista genéricamente en el artículo 66 de la Ley 39/2015 (la auténtica y genuina solicitud), y no cualquier «solicitud» de «procedimientos instrumentales» o «piezas separadas» formulada en el curso del procedimiento administrativo iniciado con la solicitud de iniciación. Por ello, el artículo 117.3 de la Ley 39/2015 expresamente excluye del deber de realizar la comunicación prevista en el artículo 21.4 a la «solicitud» de suspensión de ejecución del acto administrativo recurrido en vía administrativa, exclusión que, por cierto, tampoco es una novedad de la Ley 39/2015, por cuanto ya se dispone en el artículo 1.3 del Real Decreto 137/2010: «La emisión de la comunicación no será necesaria en los siguientes casos: a) Cuando los interesados formulen solicitudes cuya única petición sea la suspensión de la ejecución de un acto impugnado en vía de recurso $[\ldots .]$.$» .$

38. Este específico plazo de notificación del acto de trámite informativo no comienza, pues, en la fecha en que el interesado-solicitante presenta la solicitud en cualquiera de los registros administrativos de entrada distintos del registro de la Administración tramitadora, sino posteriormente, esto es, el dies... de este plazo de diez días -hábiles, según el artículo 30.2 de la Ley 39/2015- es el día en que la solicitud «entra» en el registro electrónico precisamente de la Administración tramitadora del procedimiento, y en cualquier otro registro electrónico. Por ello, el segundo párrafo del artículo 21.4 prescribe que «la comunicación indicará además la fecha en que la solicitud ha sido recibida por el órgano competente» (Ley 39/2015, artículo 21.4 párrafo segundo).

39. Recuérdese la doctrina jurisprudencial -y en particular la contenida en la Sentencia del Tribunal Superior de España 14/2006, de 14 de enero- sobre los efectos que la falta de esta comunicación produce en el plazo de interposición del recurso contencioso-administrativo contra el silencio administrativo. Véase, por todos, el exhaustivo análisis jurisprudencial que realiza (Nieto Garrido, 2006: 191-200) y, más recientemente lo han recordado, entre otros, (Gallardo Castillo, 2010: 171-172) y (Ballesteros Moffa, 2013: 111). 


\section{Ampliación del plazo}

La Ley 39/2015, no obstante establecer el deber de la Administración de resolver en plazo los procedimientos administrativos, le atribuye dos potestades administrativas relevantes que afectan al cómputo del plazo máximo de resolución/notificación y, por tanto, a la observancia misma del deber de resolver expresamente, principalmente ejercitables con el fin de evitar el vencimiento del plazo establecido y los inherentes efectos jurídico-administrativos. La primera tiene como fin la prórroga del plazo máximo de resolución, es decir, la ampliación del plazo; la segunda, en cambio, solo indirectamente implica una "prórroga» del plazo resolutorio, puesto que su finalidad esencial es la paralización temporal del plazo, esto es, la suspensión del cómputo del plazo máximo establecido. Ambas potestades administrativas han sido calificadas doctrinalmente (Cantero Martínez, 2007: 1.516) de ampliaciones del plazo resolutorio; sin embargo, los presupuestos legales habilitantes del ejercicio de una y otra potestad administrativa difieren notablemente, como veremos, por lo que difícilmente podrá calificarse a la suspensión como una modalidad «indirecta» de la ampliación del plazo y, por ello, se analizarán separadamente.

La auténtica (y única) ampliación del plazo máximo para resolver y notificar se prevé en el artículo 23 de la Ley 39/2015. El legislador, pese a atribuir a la Administración esta relevante potestad administrativa cuyo ejercicio podrá impedir la terminación anormal del procedimiento por vencimiento del plazo sin resolución expresa (el silencio administrativo o la caducidad), se la concede con carácter excepcional y subsidiario, y sujeta a un específico presupuesto de hecho y con ciertos límites. ${ }^{40}$

\section{El presupuesto previo: la ampliación de medios - personales y materiales- procedimentales y su fracaso}

En primer lugar, la ampliación del plazo máximo resolutorio solo podrá acordarla la administración pública «cuando se hayan agotado los medios personales y materiales disponibles a los que se refiere el apartado 5 del artículo 21» (Ley 39/2015: artículo 23.1); es decir, la Administración podrá ampliar el plazo máximo de resolución/notificación cuando haya ejercido la potestad organizatoria atribuida en el artículo $21.5 \mathrm{y}$, además, cuando el ejercicio de esta potestad instrumental haya sido insuficiente para garantizar un previsible resolución expresa (y notificación) en plazo.

Primero, pues, ha debido la Administración adoptar la medida organizatoria prevista en el artículo 21.5, medida que, a su vez, requiere la concurrencia de un singular y tasado presupuesto de hecho habilitante: «el número de las solicitudes formuladas

40. Lo contrario - reconocer a la Administración una amplia potestad discrecional de ampliación del plazo máximo resolutorio, sujeta exclusivamente a una motivación genérica del interés público concurrente- implicaría transferir a cada Administración una potestas variandi del plazo normativamente establecido ejercitable singularmente en cada procedimiento que así lo estimase. Nada coherente entonces con lo dispuesto en el artículo 21.2 y 21.3 . 
o las personas afectadas pudieran suponer un incumplimiento del plazo máximo de resolución» (Ley 39/2015: artículo 21.5)..$^{41}$ La apreciación de este presupuesto habilitante ${ }^{42}$ compete a la administración pública, que deberá explicitarlo suficientemente en la motivación del acuerdo administrativo de ampliación de medios. ${ }^{43}$

La primera medida administrativa prevista para evitar el incumplimiento del deber de resolver en plazo está, pues, condicionada y restringida por la Ley 39/2015 que, además, corresponde al órgano administrativo competente para resolver «a propuesta razonada del órgano instructor» $\mathrm{o}$ al «superior jerárquico del órgano competente para resolver, a propuesta de este», pero en modo alguno al órgano instructor del procedimiento, pese a que la Ley 39/2015, no solo declara su responsabilidad por la tramitación administrativa (artículo 20.1) y de su incidencia en el cumplimiento del deber de resolver en plazo (artículo 21.7), sino que también le atribuye una importante potestad administrativa genérica de adoptar las «medidas oportunas para remover los obstáculos que impidan, dificulten o retrasen [...], disponiendo lo necesario para evitar y eliminar toda anormalidad en la tramitación de procedimientos» (artículo 22.1)

Aunque, como se puede comprobar, no incluye el acuerdo de ampliación de medios establecido en el artículo 21.5 ni el acuerdo de ampliación del plazo máximo para resolver previsto en el artículo 23, sino solo su mera propuesta razonada.

En segundo término, el presupuesto de hecho legitimador del acuerdo de amplia-

41. No parece, por tanto, que una mera sobrecarga laboral sobrevenida que no derive de este supuesto de hecho habilitante pueda legitimar el acuerdo de ampliación de medios personales y materiales. La inadecuada o anquilosada organización de los servicios administrativos tramitadores o su inapropiado funcionamiento no podrá justificar esta medida administrativa excepcional. Y menos aún podrá ampararla, «la desidia, el retraso que puntualmente se pueda acumular durante la tramitación de un procedimiento o cualesquiera otras causas excepcionales» (Cantero Martínez, 2007: 1.530).

42. La Ley de España 33/2003 de Patrimonio de las Administraciones Públicas, admite un único supuesto habilitante del acuerdo de ampliación de medios $-\mathrm{y}$ consecuentemente, también del, en su caso, posterior acuerdo de ampliación del plazo máximo de resolución/notificación - con dos «modalidades»: el elevado número de «solicitudes formuladas» o el elevado número de «personas afectadas». Ambas situaciones podrán apreciarse tanto en procedimientos a solicitud como en procedimientos incoados de oficio, puesto que las numerosas solicitudes no siempre resultan ser solicitudes de iniciación stricto sensu, sino solicitudes «de personación» en procedimientos incoados de oficio, como son, por cierto, no pocos procedimientos de concurrencia competitiva o selectivos. Por otra parte, la expresión de las «personas afectadas» es desafortunada y confusa, puesto que no podrán ser otras que las personas interesadas en el procedimiento administrativo.

43. Es cierto que el artículo 21.5 no exige expresamente la motivación del acuerdo de ampliación, pero sí la exige en la propuesta del acuerdo que debe elevarse al órgano competente para acordar la ampliación de los medios personales y materiales para el despacho del asunto. Es cierto también que, en cambio, sí exige expresamente la motivación el artículo 23 para acordar la ampliación del plazo máximo de resolución/ notificación; pero precisamente al tipificarse la medida administrativa de ampliación de medios como presupuesto habilitante del acuerdo de ampliación de plazos, la adecuada motivación de éste requiere una mínima motivación de la anterior ampliación de medios acordada, siendo, además, el momento más congruente para justificar esta previa ampliación cuando se acuerda y no posteriormente cuando ha fracasado y se propone la «segunda» ampliación: la que afecta al plazo resolutorio. 
ción del plazo máximo resolutorio contemplado en el artículo 23.1 está integrado por el «agotamiento» de los medios personales y materiales disponibles facilitados al órgano administrativo tramitador al amparo del artículo 21.5. Es preciso así que la ampliación de medios acordada y ejecutada haya sido insuficiente para garantizar una previsible resolución administrativa en plazo; y es preciso también que la Administración no disponga de más medios - personales y materiales - para afectarlos a la tramitación y resolución de ese procedimiento, pues solo así se podrá entender concurrente el presupuesto habilitante («cuando se hayan agotado los medios personales y materiales disponibles», artículo 23.1 de la Ley 39/2015); solo así se habrán «agotado» los medios.

En otras palabras, aunque los medios facilitados en su momento, al amparo del artículo 21.5, no hayan bastado, si en el momento de apreciarse ese fracaso o insuficiencia se dispone de nuevos medios, el carácter excepcional y subsidiario del acuerdo de ampliación del plazo resolutorio -establecido explícitamente en el artículo 23.1 de la Ley 39/2015 - exige que, también ahora, se acuerde una ampliación de medios (y no de plazo alguno), esto es, una segunda ampliación conforme al artículo 21.5, salvo que se apreciare insuficiente para evitar el riesgo del vencimiento del plazo máximo de resolución/notificación y, consecuentemente, deba acordarse ya la ampliación del plazo resolutorio establecido normativamente.

\section{El acuerdo de ampliación del plazo máximo de resolver: requisitos intrínsecos, límites y naturaleza jurídica}

El artículo 23.1 de la Ley 39/2015 habilita «excepcionalmente» a la Administración a que, ante esa falta de medios disponibles, acuerde la ampliación del plazo. El acuerdo administrativo expreso ha de ser motivado ${ }^{44}$ y dictado bien por el órgano competente para resolver - a propuesta, en su caso, del órgano instructor-, o bien por el órgano superior jerárquico del órgano competente para resolver - a propuesta de este: según el artículo 21.5 de la misma ley-.

El único límite externo relevante que la norma impone al órgano competente para ejercer este ius variandi procedimental es el temporal: la prórroga acordada no podrá ser superior al plazo establecido legalmente para resolver y notificar la resolución de ese procedimiento. ${ }^{45}$ La discrecionalidad administrativa para determinar el quantum del nuevo plazo es, pues, notable. Y la Ley 39/2015 no dispone trámite de audiencia al-

44. La jurisprudencia ha exigido la específica y expresa motivación del acuerdo de ampliación, acorde a su tipificación como medida excepcional, evitando así que esta potestad administrativa se ejerza como una "prórroga rutinaria y generalizada, mediante el uso de fórmulas generales y estereotipadas, sin hacer mención al caso concreto planteado» (entre otras, Sentencias del Tribunal Superior de Justicia de La Rioja, de 21 de octubre de 2002 y de 24 de febrero de 2004).

45. Contrasta, por el contrario, con el límite temporal establecido en el artículo 32.1 para las ampliaciones de plazos de trámites administrativos («[... que no exceda de la mitad de los mismos»), desigualdad que, en lo referente a la ampliación solicitada por el interesado, ha sido criticada recientemente por (Santamaría Pastor, 2015: 14). 
guno previo al acuerdo administrativo de ampliación del plazo, aunque, cierto es, no lo prohíbe o limita. En todo caso, nuevamente el legislador ha establecido pocas cautelas o limitaciones a tan incisiva potestad administrativa discrecional.

Eso sí, el artículo 21.3 de la Ley 39/2015 prescribe expresamente - e innecesariamente, según su artículo 40.1- que el acuerdo administrativo ampliatorio del plazo «deberá ser notificado a los interesados». Pero lo más sobresaliente es el final: el legislador declara su impugnabilidad en vía administrativa («no cabrá recurso alguno»); es decir, su calificación de acto administrativo de trámite no cualificado - y, por tanto, inimpugnable-, rechazando a priori que ese acuerdo ampliatorio del plazo máximo resolutorio pudiera producir «indefensión o perjuicio irreparable a derechos e intereses legítimos» de los interesados, como exige el artículo 112.1, para admitir la impugnabilidad administrativa autónoma de la propia de la resolución final del procedimiento.

\section{Suspensión del cómputo del plazo}

\section{¿Dos clases de suspensiones?}

La novedad más evidente que presenta la actual regulación del deber legal de resolver expresamente los procedimientos administrativos reside en las previsiones normativas referentes a la llamada «suspensión del plazo máximo para resolver», contenidas en el artículo 22 de la Ley 39/2015 y en el anterior artículo 42.5 de la Ley 30/1992. En efecto, no solo porque se ha modificado parcialmente la tipificación específica de cierta causa de suspensión (la basada en la emisión de informes administrativos), sino porque, además, se han introducido nuevas causas legales de suspensión (procedimientos comunitarios en tramitación, resoluciones jurisdiccionales in fieri, etcétera). ${ }^{46}$

Pero lo más relevante es, sin duda, la partición del régimen jurídico de las causas suspensivas que establece la Ley 39/2015. El legislador de 2015 no ha establecido un único régimen común de los supuestos suspensivos del plazo máximo resolutorio, ${ }^{47}$ sino una dualidad de regímenes jurídico-administrativos o una dualidad de categorías de causas suspensivas. ${ }^{48} \mathrm{El}$ apartado 1 del artículo 22 recoge, cierto es, los supuestos de suspensión en términos idénticos o similares a los previstos en el artículo 42.5 de

46. En todo caso, unos y otros supuestos suspensivos constituyen causas tasadas que, por cierto, han de ser de interpretación restrictiva, como ha resaltado la doctrina y la jurisprudencia (véase, por todos, Cantero Martínez, 2007: 1.531-1.533). Así lo demanda la misma configuración legal del deber de resolver en plazo los procedimientos administrativos, no estando, pues, facultada la Administración para acordar la suspensión del plazo máximo resolutorio en cualquier otra circunstancia.

47. En la Ley 30/1992 también aprecia una mínima dualidad, no obstante, la generalidad de los supuestos de suspensión no automática que prevé el artículo 42.5 (Alonso Mas y Narbón Laínez, 2009: 31).

48. Ello, a pesar de que el artículo 22 no contiene un supuesto de suspensión exclusivo de los procedimientos incoados de oficio que está tipificado indebidamente en el artículo 25.2 de la Ley 39/2015: «En los supuestos en los que el procedimiento se hubiera paralizado por causa imputable al interesado, se interrumpirá el cómputo del plazo para resolver y notificar la resolución». 
la Ley 30/1992, ${ }^{49}$ aunque, como ya se ha indicado, añadiendo algunos más. En cambio, el apartado 2 del artículo 22 constituye una innovación legislativa «de forma y de fondo»; en primer lugar, porque las causas suspensivas que dispone expresamente no se contemplan en modo alguno en la Ley 30/1992; y, en segundo lugar, porque su grado de vinculatoriedad administrativa difiere del establecido para las causas de suspensión previstas en el artículo 22.1 de la Ley 39/2015.

Ciertamente, el artículo 22.2 prevé un acuerdo administrativo de suspensión de naturaleza reglada y de carácter preceptivo, puesto que si la administración pública aprecia la concurrencia de cualquiera de los supuestos establecidos en este apartado 2, el cómputo del plazo máximo resolutorio «se suspenderá», es decir, la Administración está obligada imperativamente ex lege a dictar un expreso acuerdo de suspensión en estos casos. Por el contrario, el artículo 22.1 parece contener unas causas suspensivas de apreciación facultativa o discrecional por la Administración («se podrá suspender», prescribe el precepto), y habilita así el legislador a la Administración para acordar motivadamente la suspensión en los términos dispuestos en la norma, o bien no acordarla y continuar, por tanto, el cómputo del plazo máximo de resolución/notificación.

El artículo 22 de la Ley 39/2015 atribuye dos clases de potestades administrativas suspensivas. La primera, tipificada en el apartado 1, es una potestad de naturaleza discrecional, sujeta, por tanto, a los límites generales y los principios propios del ejercicio de las potestades administrativas discrecionales (Ley 39/2015: artículo 35.1. letra i), por ejemplo). Por ello, no solo la apreciación administrativa de los supuestos previstos en el artículo 21.1 ha de estar especialmente justificada en mayor medida que la requerida en los acuerdos suspensivos adoptados por imperativo legal que prevé el apartado 2, sino que la decisión administrativa de suspender el cómputo del plazo debe específicamente motivarse, explicitando la ponderación de los intereses públicos y privados afectados y valorados en el acuerdo adoptado de suspensión.

La segunda potestad, la atribuida en el apartado 2, es, sin embargo, una auténtica potestad administrativa reglada. La determinación concreta del supuesto suspensivo tiene que constar suficientemente en el acuerdo de suspensión; pero nada más, en cuanto que, acreditada la causa legal, la motivación del acuerdo suspensivo no es tan relevante al tratarse de una actuación administrativa reglada.

\section{Suspensión discrecional}

La Ley 39/2015 la prevé en su artículo 22.1: «El transcurso del plazo máximo legal para

49. Se mantiene, pues, la justificación de la generalidad de las críticas doctrinales a la regulación de las causas de suspensión, así como las propuestas de lege ferenda formuladas, como, por ejemplo, las amparadas en la simplificación administrativa y la «buena administración» postuladas por (Pérez Monguió, 2014:317): «[...] Así, como propuesta podría establecerse la necesidad de establecer los plazos máximos de suspensión en cada procedimiento. Un plazo que podría incluso ser superior a lo que inicialmente sería razonable, pues en el caso de que se evacuase con anterioridad a la finalización del mismo, inmediatamente debería continuarse con la tramitación del procedimiento [...]». 
resolver un procedimiento y notificar la resolución se podrá suspender en los siguientes casos: [...]». Este precepto dispone siete supuestos de suspensión; los cinco establecidos en el artículo 42.5 de la Ley 30/1992 y dos nuevos supuestos añadidos. A efectos meramente expositivos y convencionales se examinarán agrupados en atención a características o fundamentos comunes.

\section{Los trámites pendientes como causas suspensivas}

Un primer grupo de causas suspensivas está amparado por la propia ordenación normativa de la instrucción del procedimiento, puesto que la regulación procedimental dispone trámites preceptivos relevantes, determinantes o vinculantes, en su caso, de la resolución final del procedimiento. Y como la práctica de estos trámites no compete a la Administración actuante y responsable del procedimiento, no se le debe imputar el cómputo de los plazos que legalmente se disponen para la evacuación de dichos trámites, justificándose así la suspensión del plazo máximo de resolución/notificación durante esos plazos normativamente establecidos. No importa, pues, que el trámite deba realizarlo el interesado o un órgano de otra administración pública; no importa tampoco que el trámite competa a un órgano administrativo o a un órgano de otras instituciones o poderes públicos; lo relevante es que su realización corresponda a un tercero y no a la Administración, que tiene legalmente el deber de resolver y notificar la resolución en plazo.

\section{La evacuación de trámites imputables a los interesados}

El artículo 22.1 de la Ley 39/2015 contiene dos causas que justifican la suspensión potestativa del plazo máximo resolutorio por imputarse al interesado la práctica de ciertos trámites del procedimiento. ${ }^{50}$ La primera de ellas es la tipificada en la letra a):

Cuando deba requerirse a cualquier interesado para la subsanación de deficiencias o la aportación de documentos y otros elementos de juicio necesarios, por el tiempo que medie entre la notificación del requerimiento y su efectivo cumplimiento por el destinatario, o, en su defecto, por el del plazo concedido, todo ello sin perjuicio de lo previsto en el artículo 68 de la presente ley (artículo 22.1 letra a) de la Ley de España 39/2015).

Como se puede apreciar, la suspensión se basa en la ausencia de documentos o datos en el procedimiento que el interesado debe aportar. Pero la norma prevé dos supuestos

50. Aparte de estas dos, es preciso recordar la causa establecida en el artículo 25.2 de la Ley 39/2015: ( En los supuestos en los que el procedimiento se hubiera paralizado por causa imputable al interesado, se interrumpirá el cómputo del plazo para resolver y notificar la resolución»), que, por su similitud con la dispuesta en el artículo 22.1 letra a), tratándose de procedimientos incoados de oficio y dado el carácter tasado y excepcional de las causas suspensivas automáticas, ha de calificarse como causa de suspensión discrecional. 
suspensivos: los defectos u omisiones que presentan los documentos facilitados por el interesado y la falta misma de esos documentos o datos; en ambos casos, el interesado ha de estar obligado legalmente a facilitar esa información o documentación de conformidad con lo dispuesto, primeramente, en el artículo 28 de la Ley 39/2015. ${ }^{51}$

Especial interés presenta el supuesto de las deficiencias informativas o documentales que la ley reclama, por cuanto nos remite al conocido trámite de subsanación de defectos de la documentación facilitada por el interesado, establecido genéricamente en el artículo 73.2 de la Ley 39/2015. El plazo para tal subsanación -dispuesto en este precepto- es de diez días (hábiles), que, por tanto, es también el término de suspensión del plazo máximo resolutorio, ${ }^{52}$ salvo que la subsanación se realice con anterioridad al vencimiento del décimo día. De esta forma, los efectos jurídico-administrativos de la inactividad del interesado por no subsanar el trámite en plazo no se limitan, por consiguiente, a la pérdida del derecho al trámite no subsanado (Ley 39/2015: artículo 73.3), sino que también afectan al plazo máximo para resolver el procedimiento en virtud de lo dispuesto en este artículo 21.1 letra a).53

La segunda causa suspensiva imputable al interesado es más difícil de justificar. El artículo 21.1 letra e) prescribe la suspensión potestativa «cuando deban realizarse pruebas técnicas o análisis contradictorios o dirimentes propuestos por los interesados, durante el tiempo necesario para la incorporación de los resultados al expediente» (artículo 21.1 letra e) de la Ley 29/2015). En primer lugar, porque las pruebas técnicas o analíticas referidas no necesariamente requieren un plazo de realización superior al precisado para la práctica de otras clases de pruebas en el procedimiento administrativo (numerosas o complejas testificales, documentales...); en otras palabras, la naturaleza de las pruebas periciales no implica per se una mayor duración que la propia de otros

51. El apartado 1 dispone la obligación de aportar al procedimiento administrativo los datos y documentos exigidos por las administraciones públicas, solo «de acuerdo con lo dispuesto en la normativa aplicable» (Ley 39/2015: artículo 28.1). Obsérvese también que el apartado 3 expresamente prohíbe a las Administraciones exigir a los interesados «datos o documentos no exigidos por la normativa reguladora aplicable o que hayan sido aportados anteriormente por el interesado a cualquier Administración» (Ley 39/2015: artículo 28.3), y solo «excepcionalmente, si las administraciones públicas no pudieran recabar los citados documentos, podrán solicitar nuevamente al interesado su aportación» (Ley 39/2015: artículo 28.3). Es más, incluso tratándose de documentos de preceptiva aportación establecida por la normativa específica del procedimiento, «los interesados no estarán obligados a aportar documentos que hayan sido elaborados por cualquier Administración [...], siempre que el interesado haya expresado su consentimiento a que sean consultados o recabados dichos documentos [...]» (Ley 39/2015: artículo 28, apartado 2). Véase (González Bustos, 2016: 87-90).

52. Cf. en relación a su antecedente de la Ley 30/1992 (Alonso Mas y Narbón Laínez, 2009: 41).

53. Por el contrario, si el acto-trámite defectuoso es la solicitud de iniciación, el único efecto de la no subsanación en plazo es el previsto en el artículo 68.1 de la Ley 39/2015, al que expresamente remite el artículo 21.1 letra a): la terminación anormal del procedimiento y no, en modo alguno, mera suspensión del plazo máximo resolutorio. Tratándose de la solicitud de iniciación, el genérico efecto de la pérdida del derecho al trámite o subsanado (Ley 39/2015: artículo 73.3) se transforma en el específico efecto de la pérdida del derecho al procedimiento (Ley 39/2015: artículo 68.1). 
medios de prueba; ${ }^{54}$ unas y otras pruebas, por cierto, podrán practicarse en un plazo máximo no corto precisamente (treinta días) y adicionalmente, en un plazo extraordinario, conforme se dispone en el artículo 77.2 de la Ley 39/2015.

Y, en segundo lugar, si es la singularidad de este de medio probatorio lo que justifica su explícita previsión como supuesto suspensivo, lo justificaría con independencia de la parte que haya propuesto la prueba técnica o analítica, esto es, tanto si la propone el interesado como si la acuerda de oficio la Administración. Si, en cambio, es la instancia de parte interesada en la proposición de la prueba -y no su proposición administrativa «de oficio»- lo que avala su tipificación como causa suspensiva, se olvida que toda solicitud de práctica de prueba formulada por el interesado ha de ser admitida y acordada por la Administración cuando sea procedente o necesaria conforme dispone el artículo 77.3 de la Ley 39/2015, y le corresponde, pues, a la Administración la decisión misma de admitir la prueba propuesta y de acordar el plazo y demás condiciones de su práctica, en virtud de lo dispuesto en el artículo 77.2, no debiendo asimilarse este supuesto a otros en los que el responsable del trámite pendiente es exclusivamente el interesado.

\section{La evacuación de trámites imputable a otra Administración, Poder o institución pública}

La mayoría de las causas de suspensión potestativa establecidas en el artículo 21.1 se pueden reconducir a ciertos trámites preceptivos que han de realizar Administraciones o instituciones públicas distintas de la tramitadora y resolutoria del procedimiento administrativo en curso. Aun así, los supuestos presentan interesantes diferencias en cuanto a la misma configuración de sus presupuestos jurídicos esenciales normativamente tipificados.

El presupuesto de la causa suspensiva tipificada en la letra d) está constituido por la emisión de un informe administrativo, ${ }^{55}$ tanto por parte de un órgano de la propia administración pública actuante -que se analizará más adelante-como por parte de un órgano de otra administración pública. Pero no cualquier informe administrativo podrá justificar la suspensión del plazo máximo resolutorio, porque el artículo 21.1 letra d) exige que el informe sea, en todo caso, preceptivo; esto es, el ordenamiento administrativo ha de establecerlo expresa y explícitamente con este carácter que, en modo alguno, podrá inferirse o presumirse de lo dispuesto en la normativa reguladora del

54. Y es precisamente la mayor duración de este tipo de pruebas en comparación con las testificales o documentales, por ejemplo, lo que justifica la aceptación de la suspensión por la jurisprudencia, aunque solo durante el tiempo que sea estrictamente necesario para la realización de la prueba. En este sentido, amparándose en «la propia complejidad que plantea la práctica de aquellas diligencias y por el largo período de tiempo que puede llevar su realización» lo acepta (Cantero Martínez, 2007: 1536).

55. Por ello, como ha recordado (Cantero Martínez, 2007: 1535), «la petición del informe o atestado de la Guardia Civil ratificando una denuncia no pueda ser considerado a estos efectos como un «informe técnico preceptivo», pues simplemente se trata de una ratificación y ampliación de la denuncia propia de una prueba testifical (STSJ [Sentencia del Tribunal Superior de Justicia] de La Rioja, de 28 de febrero de 2002)». 
procedimiento. ${ }^{56} \mathrm{La}$ suspensión del cómputo temporal procedimental podrá así acordarse porque la Administración actuante necesita - por imperativo legal- para poder resolver el procedimiento, que previamente sea emitido un informe por parte de otra administración pública; en modo alguno la Ley 39/2015 prevé una suspensión del plazo procedimental con carácter automático ante la mera petición de un informe administrativo, por cuanto tratándose de un informe facultativo la Administración no está facultada para acordar suspensión alguna y, por el contrario, sí está «facultada» explícitamente para continuar la tramitación del procedimiento (Ley 39/2015: artículo 80.4).

Pero la Ley 39/2015 ya no exige -a diferencia de su antecedente previsto en el artículo 42.5 letra c) de la Ley 30/1992- que el informe, además de ser preceptivo, sea «determinante»..$^{57} \mathrm{La}$ Administración actuante podrá, pues, acordar la suspensión ante la emisión de cualquier informe administrativo preceptivo, sea vinculante o no, determinante o no del contenido de la resolución, informe que, por cierto, ha de emitirse «en el plazo de diez días, salvo que una disposición o el cumplimiento del resto de los plazos del procedimiento permita o exija otro plazo mayor o menor» (Ley 39/2015: artículo 80.2).

El cómputo del plazo máximo resolutorio podrá así suspenderse desde la fecha del acto administrativo de trámite solicitando la emisión del preceptivo informe a la otra administración pública hasta la fecha de recepción del informe por el órgano administrativo solicitante, ${ }^{58}$ debiendo notificarse ambas fechas a los interesados (artículo 22.1 letra d) de la Ley 39/2015). ${ }^{59}$ Por ello, el plazo de duración de la suspensión podrá ser superior al plazo establecido normativamente para emitir el preceptivo informe; es cierto que el artículo 80.4 de la Ley 39/2015 prescribe la continuidad del procedimiento («se podrán proseguir las actuaciones») —es decir, el fin de la suspensión acordada- si

56. Porque el artículo 80.1 de la Ley 39/2015 dispone, como norma general común y como norma supletoria de la específica regulación procedimental («salvo disposición expresa en contrario») que «los informes serán facultativos y no vinculantes».

57. La supresión de singular concepto jurídico indeterminado es acertada, dada su difícil delimitación con su próximo concepto «vinculante» (véase, por todos, Cierco Seira, 2002: 88-91). Alaba también su desaparición en el entonces Anteproyecto de Ley, (Santamaría Pastor, 2015: 6).

58. Obsérvese que el dies ad quem del plazo suspensivo no es el día de la recepción («notificación») de la petición del informe en el registro de la administración pública cuyo órgano ha de emitirlo, sino la fecha de la petición administrativa, diferenciándose, por cierto, del establecido en la letra a) que sí es el día de la «notificación» del acto de trámite (requerimiento de subsanación) y no la fecha del acto. En cambio, el dies a quo dispuesto en la norma es el día de la recepción del informe en el registro de la Administración peticionaria y actuante.

59. La jurisprudencia ha resaltado la relevancia de esta específica notificación administrativa como requisito de eficacia misma del acuerdo suspensivo del plazo máximo resolutorio; así, por ejemplo, la Sentencia del Tribunal Superior de Justicia de Castilla-La Mancha, de 4 de octubre de 2004, recuerda que «la Ley 30/1992, inspirada en principios de seguridad jurídica, pretende que los interesados conozcan cuál es el plazo máximo de resolución del expediente (véase, por ejemplo, el artículo 42.4) y choca con esta intención legal evidente el hecho de que pueda considerarse suspendido el plazo de resolución sin que el interesado lo sepa claramente» (Fundamento Jurídico). 
transcurriera ese plazo establecido sin que el informe se hubiera emitido; pero, cuando el informe es preceptivo, acordándose potestativamente la suspensión, rige la regulación especial prevista en el artículo 22.1 letra d) que, como se ha indicado, prescribe como día final del plazo suspensivo el día de la recepción del informe, con independencia del plazo legalmente dispuesto para su emisión. Eso sí, «este plazo de suspensión no podrá exceder en ningún caso de tres meses» (artículo 22.1 letra d) de la Ley 39/2015), debiendo reanudarse el cómputo del plazo máximo resolutorio al día siguiente del vencimiento de dicho plazo como prescribe el precepto («[...] En caso de no recibirse el informe en el plazo indicado, proseguirá el procedimiento»). ${ }^{60}$

El artículo 21.1 prescribe dos supuestos suspensivos basados en la afectación que ciertos procedimientos administrativos de la Unión Europea originen en el procedimiento administrativo español. El primer supuesto ya está previsto en el artículo 42.5 de la Ley 30/1992, pero el segundo es novedoso en nuestra legislación de procedimiento administrativo común. En ambos casos, llama la atención que la Ley 39/2015 no haya establecido un plazo máximo de eficacia o duración de la suspensión acordada, a diferencia de lo que el mismo artículo 21.1 prevé en relación a los anteriores supuestos de suspensión, ${ }^{61}$ bien expresa y directamente (artículo 21.1 letra d) de la Ley 39/2015: «[... ] tres meses»), bien implícitamente (artículo 21.1 letra a) de la Ley 39/2015: «[...] o, en su defecto, por el del plazo concedido») o bien en aplicación de otros preceptos de la propia Ley 39/2015 ( artículo 21.1 letra e): por el artículo 77.2).

El primer supuesto -tipificado ya en la Ley 30/1992- se contempla en la letra b) en los siguientes términos:

Cuando deba obtenerse un pronunciamiento previo y preceptivo de un órgano de la Unión Europea, por el tiempo que medie entre la petición, que habrá de comunicarse a los interesados, y la notificación del pronunciamiento a la Administración instructora, que también deberá serles comunicada (artículo 22.1 letra b) de la Ley 39/2015).

El trámite administrativo comunitario ha de estar tipificado como obligatorio en el ordenamiento comunitario y español; y podrá consistir tanto en una resolución final de un procedimiento administrativo de la Unión Europea que se haya establecido como trámite previo y preceptivo a la resolución del procedimiento administrativo del Estado miembro, como en un acto de trámite (comunitario) stricto sensu que implique

6o. No es, pues, aplicable la norma dispuesta en el último párrafo del artículo 80.4 («El informe emitido fuera de plazo podrá no ser tenido en cuenta al adoptar la correspondiente resolución»), porque el artículo 22.1 letra d) admite el informe extemporáneo o tardío - siempre que sea preceptivo- vencido el plazo normativamente previsto para su emisión, Así, el preceptivo informe tardío solo "podrá no ser tenido en cuenta» al adoptarse la resolución cuando se haya emitido después de ese plazo máximo de tres meses y, por aplicación del artículo 35.1 letra c) de la Ley 39/2015, no sea un dictamen de un órgano consultivo o, cuando lo sea, se motive debidamente su no consideración por el órgano competentes para resolver el procedimiento.

61. Así lo ha criticado, respecto del antecedente dispuesto en el artículo 42.5 letra b) de la Ley 30/1992, (Arzoz Santistebán, 2001: 107). 
un "pronunciamiento», esto es, un informe/dictamen o una propuesta de resolución. ${ }^{62}$

En cambio, el segundo supuesto -dispuesto en la letra c)- no está basado en la preceptiva emisión de un cierto acto comunitario de trámite, sino en una auténtica resolución final de un procedimiento comunitario que aún no se ha dictado («Cuando exista un procedimiento no finalizado en el ámbito de la Unión Europea [...]»). ${ }^{63}$ Eso sí, la resolución comunitaria ha de establecerse normativamente como preceptiva y previa a la resolución del procedimiento administrativo nacional y, además, establecerse como vinculante o determinante de la resolución del procedimiento administrativo del Estado miembro («[...] procedimiento no finalizado [...] que condicione directamente el contenido de la resolución de que se trate [...]»).

Por último, aparte de que la duración de la suspensión declarada por esta causa no tiene establecida un límite temporal, la norma es aún más deficiente, por cuanto tampoco la determinación del dies ad quem del plazo suspensivo es acertada al permitirse a la Administración actuante «apreciar» la fecha en que ha tenido «constancia» de la existencia de ese procedimiento comunitario aún no terminado.

El artículo 21.1 letra g) introduce una nueva causa de suspensión del plazo máximo resolutorio: la basada en la necesaria emisión de una resolución jurisdiccional:

Cuando para la resolución del procedimiento sea indispensable la obtención de un previo pronunciamiento por parte de un órgano jurisdiccional, desde el momento en que se solicita, lo que habrá de comunicarse a los interesados, hasta que la Administración tenga constancia del mismo, lo que también deberá serles comunicado (artículo 21.1 letra g) de la Ley 39/2015).

Ahora bien, la norma no prescribe que ese pronunciamiento jurisdiccional -no necesariamente judicial- esté tipificado en el ordenamiento jurídico-administrativo como un trámite preceptivo para resolver el procedimiento administrativo, sino solo que resulte ser «indispensable» para la resolución administrativa; así, la inclusión de este novedoso concepto jurídico indeterminado como presupuesto esencial de esta causa suspensiva en una ley de procedimiento administrativo común no parece ser un acierto por la notable inseguridad jurídica que genera el ejercicio de la amplísima discrecionalidad administrativa reconocida para la determinación del concepto jurídico; demandando, por tanto, una mínima especificación y explicitación del concepto aunque se efectúe por vía reglamentaria.

Ciertamente, como no están descritos normativamente los supuestos -o al menos,

62. En la misma línea, con la Ley 30/1992 ya se manifiesta (Parejo Alfonso, 1999: 131).

63. La expresión utilizada para referirse al procedimiento comunitario es desafortunada, puesto que interpretando literalmente «en el ámbito de la Unión Europea» podría incluirse no solo a los procedimientos de las instituciones comunitarias, sino también a los procedimientos administrativos nacionales de otros Estados miembros de la Unión, al amparo, por ejemplo, de lo dispuesto en un convenio internacional bilateral celebrado entre España y otro Estado comunitario. Si fuera esta la intención del legislador, debería reformar el precepto y delimitar nítidamente los procedimientos determinantes de esta causa suspensiva procedimental. 
los criterios delimitadores- en que es indispensable ese previo pronunciamiento jurisdiccional para la resolución del procedimiento administrativo, podría interpretarse que exclusivamente un pronunciamiento de la jurisdicción penal podría ser «indispensable» para la resolución administrativa. Y ello porque los pronunciamientos jurisdiccionales civiles o laborales ni siquiera están previstos como indispensables para las resoluciones de los procesos contencioso-administrativos -menos aún para las resoluciones de los procedimientos administrativos- sino únicamente como cuestiones prejudiciales o incidentales en el proceso contencioso-administrativo (Ley 29/1998: artículo 4).

Así, pues, en principio, en la Ley 39/2015 apreciamos dos únicos supuestos subsumibles en esta causa suspensiva. El primero, también señalado con acierto por Santamaría Pastor (2015: 6), está constituido por la sentencia penal condenatoria «indispensable» para la resolución administrativa de nulidad de pleno derecho que pone fin al procedimiento administrativo anulatorio -sea incoado de oficio (Ley 39/2015: artículo 106.1) o iniciado a instancia de parte interesada (Ley 39/2015: artículos 106.1 y 112.1)- de actos nulos por ser constitutivos de infracción penal o dictados como consecuencia de ella (artículo 47.1 letra d) de la Ley 39/2015). El segundo caso es propio del ejercicio mismo de la potestad administrativa sancionadora (derogado Real Decreto 1398/1993, de 4 de agosto, por el que se aprueba el Reglamento del Procedimiento para el Ejercicio de la Potestad Sancionadora: artículo 7) y de la observancia de uno de los principios generales del derecho sancionador, estando más explícitamente tipificado el pronunciamiento jurisdiccional penal como «indispensable» para la resolución administrativa en el artículo 77.4 de la Ley 39/2015: «En los procedimientos de carácter sancionador, los hechos declarados probados por resoluciones judiciales penales firmes vincularán a las administraciones públicas respecto de los procedimientos sancionadores que substancien» (Ley 39/2015: artículo 77.4).

\section{La evacuación de trámites imputable a la misma Administración actuante}

El artículo 21.1 letra d) de la Ley 39/2015 tipifica, como ya se ha anticipado, un segundo supuesto suspensivo, también contemplado en el antecedente dispuesto en el artículo 42.5 letra c) de la Ley 30/1992. La emisión de un informe administrativo por un órgano de la propia administración pública tramitadora del procedimiento podrá fundamentar el acuerdo de suspensión del cómputo del plazo máximo resolutorio, siempre que sea preceptivo, como exige expresamente la letra d) del artículo 21.1. Parece, pues, que la propia Administración responsable del cumplimiento del deber legal de resolver en plazo -única responsable de la tramitación procedimental- podrá acordar la suspensión de ese plazo alegando su previsible vencimiento por estar pendiente la evacuación de un preceptivo informe. ${ }^{64}$

64. Lo cierto es que, como ha subrayado acertadamente (Santamaría Pastor, 2015: 6), no está justificada esta causa suspensiva por cuanto desnaturalizaría la misma regulación procedimental que ha debido establecer ese preceptivo trámite del informe con un plazo determinado de evacuación y, considerando todos 
Es más, el artículo 80.3 de la Ley 39/2015 permite que la Administración acuerde la suspensión incluso una vez vencido el plazo de emisión del informe sin que se haya emitido. ${ }^{65}$ Eso sí, el artículo 21.1 letra d) impide la continuidad del plazo suspensivo cuando el plazo haya superado los tres meses ${ }^{66}$ y no se haya recepcionado el informe, en cuyo caso debe proseguir el procedimiento.

\section{La corresponsabilidad en el fracaso de la terminación convencional}

Si durante la tramitación del procedimiento administrativo se inician negociaciones entre el interesado y la Administración para acordar la terminación bilateral prevista en el artículo 86 de la Ley 39/2015, la Administración podrá acordar la suspensión del plazo máximo resolutorio durante el proceso negociador, siempre que dicte un específico acto de trámite de iniciación del "procedimiento negociador» («desde la declaración formal al respecto») y también un acto de trámite declarando su finalización («que se constatará mediante declaración formulada por la Administración o los interesados») ${ }^{67}$ y, por tanto, reanudar el cómputo del plazo máximo de resolución y notificación del procedimiento administrativo.

\section{Suspensión reglada}

Los tres nuevos casos de suspensión preceptiva o reglada para la administración pública se tipifican en el artículo 22.2 de la Ley 39/2015: «El transcurso del plazo máximo legal para resolver un procedimiento y notificar la resolución se suspenderá en los siguientes casos: $[\ldots]$ ».

\section{La causa suspensiva exclusiva de los procedimientos impugnatorios interadministrativos}

La letra a) así lo prescribe:

Cuando una administración pública requiera a otra para que anule o revise un acto que entienda que es ilegal y que constituya la base para el que la primera haya de dic-

los trámites y plazos inherentes, el plazo máximo de resolución y notificación.

65. «De no emitirse el informe en el plazo señalado, y sin perjuicio de la responsabilidad en que incurra el responsable de la demora, se podrán proseguir las actuaciones salvo cuando se trate de un informe preceptivo, en cuyo caso se podrá suspender el transcurso del plazo máximo legal para resolver el procedimiento en los términos establecidos en la letra d) del apartado 1 del artículo 22» (Ley 39/2015: artículo 80.3).

66. Especialmente crítico con este plazo trimestral establecido en el antecedente del artículo 42.5 letra c) de la Ley 30/1992 se ha manifestado (Pérez Monguió, 2014: 317): «[...] Plazo que resulta excesivo. No es razonable que un informe que deba emitir una Administración pueda tardar en evacuarse el plazo legal supletorio máximo para la resolución de un expediente [...]».

67. Sorprende una vez más este apartado final de la norma, por cuanto en modo alguno un acto del interesado declarando unilateralmente el fin de la negociación podrá determinar per se el fin del plazo suspensivo acordado por la Administración. 
tar en el ámbito de sus competencias, en el supuesto al que se refiere el apartado 5 del artículo 39 de esta ley [...]» (artículo 22.2 letra a) dela Ley 39/2015).

El presupuesto habilitante del preceptivo y reglado acuerdo administrativo de suspensión está, pues, integrado por tres elementos inexcusables: 1.- la Administración actuante debe dictar un acto administrativo -la resolución o un acto de trámite- que «necesariamente tenga por base otro dictado por una administración pública distinta» (Ley 39/2015: artículo 39.5), requisito, por cierto, no de fácil apreciación pese al ejercicio de competencias colaborativas o cooperativas entre Administraciones en ciertos procedimientos administrativos de instrucción y resolución atribuida a una única Administración colaboradora; 2.- la Administración actuante debe apreciar una (o varias) causas de invalidez en el acto administrativo de la otra Administración; 3.- la Administración actuante debe interponer un requerimiento interadministrativo de anulación/ revocación por motivos de legalidad del citado acto administrativo externo.

De esta forma, la suspensión solo podrá y deberá acordarse cuando se haya iniciado el conflicto interadministrativo procedimentalizado mediante el requerimiento impugnatorio previsto en el artículo 39.5 de la Ley 39/2015 y el artículo 44 de la Ley 29/1998; este requerimiento interadministrativo ha de interponerlo la Administración actuante en el plazo máximo de dos meses desde que conoce el acto que afecta al ejercicio de sus competencias (Ley 29/1998: artículo 44.2), y debe responderse expresamente por la Administración requerida en el plazo máximo de un mes, entendiéndose desatendido si no se ha notificado respuesta en ese plazo (Ley 29/1998: artículo 44.3) y estando así legitimada la Administración requirente para interponer el recurso contencioso interadministrativo.

Por último, el artículo 21.2 letra a) introduce indirectamente un cuarto elemento indispensable en la tipificación de la causa resolutoria: la existencia de terceros interesados afectados por los actos dictados por las dos Administraciones y, por tanto, interesados en el procedimiento administrativo cuyo plazo máximo resolutorio se tiene que suspender preceptivamente «desde que se realiza el requerimiento hasta que se atienda o, en su caso, se resuelva el recurso interpuesto ante la jurisdicción contencioso administrativa» (Ley 39/2015: artículo 22.2 letra a). En efecto, la norma dispone que «deberá ser comunicado a los interesados tanto la realización del requerimiento, como su cumplimiento o, en su caso, la resolución del correspondiente recurso contenciosoadministrativo» (Ley 39/2015: artículo 22.2 letra a); se requiere así que el conflicto interadministrativo afecte a un tercero, y no exclusivamente a las dos administraciones públicas en litigio, esto es, que sea un procedimiento administrativo con administrado interesado y, por ello, se justifica la suspensión administrativa del plazo máximo de resolución y notificación.

\section{La suspensión determinada por la «instrucción complementaria»}

El artículo 21.2 letra b) prescribe una nueva causa resolutoria de carácter preceptivo y, por tanto, de difícil justificación: el acto de trámite dictado por el órgano competente 
para resolver, acordando motivadamente, la práctica de las llamadas «actuaciones complementarias» tipificadas específicamente en el artículo 87, cuyo apartado final también dispone la suspensión del plazo máximo resolutorio hasta que terminen las actuaciones complementarias. ${ }^{68} \mathrm{Y}$ no es acertada la introducción de este supuesto suspensivo, porque así la Ley 39/2015 impone una prórroga o ampliación automática del plazo máximo resolutorio por la mera adopción de un acuerdo administrativo de trámite instrumental de la resolución, con una funcionalidad y justificación, pues, ajena a la debida y congruente para suspender el cómputo del plazo de resolución procedimental; ciertamente, el acuerdo de actuaciones complementarias ha de motivarse precisamente por ser indispensable para resolver debidamente el procedimiento y, en consecuencia, no necesita estar fundamentado en causa objetiva sobrevenida, imprevista e imprevisible que, afectando a la continuidad de la instrucción, sin embargo, no le sea imputable a la administración pública actuante y, por tanto, responsable de la tramitación y resolución en plazo.

\section{La cuestión incidental de la recusación}

El tercer y último supuesto de suspensión obligada está constituido por el incidente de recusación interpuesto por el interesado por apreciar en el empleado o cargo público interviniente en el procedimiento alguna de las causas de abstención ${ }^{69}$ establecidas en el artículo 23.2 de la Ley 40/2015. El acuerdo administrativo de suspensión del plazo máximo resolutorio no procede cuando, de oficio, la propia administración pública -el incurso en la causa de abstención o su superior jerárquico- aprecia la causa de abstención conforme dispone el artículo 23.1 y 23.3 de la Ley 40/2015. Solo cuando la causa de abstención se ha alegado mediante solicitud de parte interesada, esto es, cuando se ha formulado el acto jurídico-administrativo (y la pretensión inherente) de la recusación, es cuando se debe suspender la duración del procedimiento; en suma, solo cuando -en cualquier momento del procedimiento administrativo (Ley 40/2015: artículo 24.1; artículo 21.2 letra c) de la Ley 39/2015) - se ha iniciado por el interesado el trámite del incidente -pieza procedimental separada- de recusación está justificada la suspensión automática del plazo máximo resolutorio del procedimiento; lo confirma el único precepto de la Ley 39/2015 exclusivo y específico de las "cuestiones incidentales», al prescribir la no suspensión del procedimiento salvo que la cuestión incidental sea la recusación (Ley 39/2015: artículo 74).

68. El día inicial del plazo suspensivo es la fecha en que se notifica a los interesados el acuerdo motivado de las actuaciones complementarias (artículo 21.2 letra b) de la Ley 39/2015); y el día final es la fecha del fin de dichas diligencias de instrucción que han de practicarse en un plazo máximo de quince días (Ley 39/2015: artículo 87). El periodo de suspensión no incluye, pues, el específico plazo de siete días de alegaciones posterior al fin de las actuaciones complementarias, aunque se les notifique en el acuerdo de la práctica de dichas diligencias (Ley 39/2015: artículo 87).

69. Véase, por todos, (Fernández Ramos y Pérez Monguió, 2012) y (Doménech Pascual, 2002: 450 y ss.). 
El periodo suspensivo comienza desde que el interesado "plantea» la recusación ${ }^{70}$ «hasta que sea resuelta por el superior jerárquico del recusado» (artículo 21.2 letra c) de la Ley 39/2015). En todo caso, dada la escasa duración de la tramitación y resolución del incidente de la recusación que establece el artículo 24 de la Ley 40/2015 (un día más tres días, como máximo), es dudosa su justificación como genérico supuesto de preceptiva suspensión y su misma utilidad, salvo en los procedimientos administrativos de tramitación simplificada y, por tanto, con un plazo máximo resolutorio que no debe superar en exceso los treinta días que se establecen para la tramitación simplificada (Ley 39/2015: artículo 96.6).

\section{Referencias}

Aguado I Cudolà, Vicenç (2012). «El silencio administrativo: proceso evolutivo y claves del régimen actual». En Tomás Quintana López (director) y Marcos Anabelén Casares (coordinador), Silencio administrativo. Estudio general y procedimientos sectoriales. Valencia: Tirant lo Blanch.

Alonso IbÁÑEZ, Rosario (2012). «Capítulo III. El incumplimiento de la obligación de resolver». En Tomás Quintana López (director) y Marcos Anabelén Casares (coordinador), Silencio administrativo. Estudio general y procedimientos sectoriales. Valencia: Tirant lo Blanch.

ALOnso Mas, María José y Edilberto José Narbón Laínez (2009). El silencio administrativo y su problemática procesal. Valencia: Tirant lo Blanch.

Arzoz Santistebán, Xabier (2001). La obligación de resolver y notificar y el silencio administrativo. Barcelona: Marcial Pons.

Ballesteros MofFa, Luis Ángel (2013). «La capitulación del acto consentido y firme ante el silencio negativo». Revista de Administración Pública, 192: 99-135.

CANTero Martínez, Josefa (2007). «Obligación de resolver y silencio administrativo». En José Garberí Llobregat (coordinador), El procedimiento administrativo común. Tomo II. Valencia: Tirant lo Blanch.

Cierco Seira, César (2002). «El ejercicio extemporáneo de la función consultiva». Revista de Administración Pública, 158: 77-118.

Doménech PAscual, Gabriel (2002). «La abstención en el procedimiento administrativo». En José María Baño León y Juan Climent Barberá (coordinadores), Nuevas perspectivas del régimen local: estudios en homenaje al profesor José $M^{a}$ Boquera Oliver. Valencia: Tirant lo Blanch.

Entrena Cuesta, Rafael (2002). «La obligación de resolver y la nueva regulación del silencio administrativo». En José María Baño León y Juan Climent Barberá (coordi-

70. La tipificación de este dies ad quem es defectuosa, al igual que su insuficiente y específica previsión procedimental en el artículo 24 de la Ley 40/2015, debiendo referirse el acto de promover-plantear la recusación al acto de presentación del escrito de recusación en cualquiera de los registros administrativos previstos en el artículo 16.4 de la Ley 39/2015, con independencia de la fecha de recepción del escrito por el órgano administrativo instructor o resolutorio del procedimiento. 
nadores), Nuevas perspectivas del régimen local: estudios en homenaje al profesor José $M^{a}$ Boquera Oliver. Valencia: Tirant lo Blanch.

Fernández Ramos, Severiano y José María Pérez Monguió (2012). La imparcialidad en el procedimiento administrativo: abstención y recusación. Cizur Menor (Navarra): Thomson Reuters-Aranzadi.

FERnÁndez VAlverde, Rafael (200o). «De nuevo, ante el silencio administrativo». Revista Española de Derecho Administrativo, 105: 79-102.

Gallardo Castillo, María Jesús (2010). Régimen jurídico de las Administraciones Públicas y Procedimiento Administrativo Común. Comentario sistemático a la Ley 30/1992, de 26 de noviembre. Madrid: Tecnos.

Gómez Puente, Marcos (200o). La inactividad de la Administración. $2^{\mathrm{a}}$ ed. Cizur Menor (Navarra): Aranzadi.

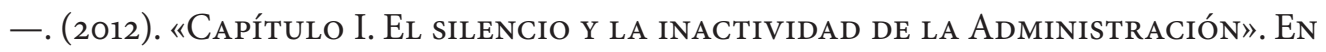
Tomás Quintana López (Director) y Marcos Anabelén Casares (COORdinaDOR), Silencio administrativo. Estudio general y procedimientos sectoriales. Valencia: Tirant lo Blanch.

GonzÁlez Bustos, María Ángeles (2016). «La actividad de información y documentación de la Administración pública». En Ricardo Rivero Ortega, María Dolores Calvo Sánchez y Marcos Fernando Pablo (directores), Instituciones de Procedimiento Administrativo Común. Novedades de la Ley 39/2015. Lisboa: Juruá.

Morillo-Velarde Pérez, José Ignacio (2002). «El silencio administrativo tras la reforma de 1999. Un cambio inadvertido y unas posibilidades inéditas». Revista de Administración Pública, 159: 87-136.

Nieto Garrido, Eva María (2006). «Silencio administrativo y acceso a la jurisdicción en la reciente jurisprudencia del Tribunal Constitucional. A propósito de las SSTC 14/2006, de 16 de enero, y 39/2006, de 13 de febrero». Revista de Administración Pública, 170: 191-200.

Parejo Alfonso, Luciano José (1999). «La nueva regulación del silencio administrativo». Documentación Administrativa, 254-255: 111-158.

PÉrez Monguió, José María (2014). «Capítulo noveno. Criterios de agilización del procedimiento». En Eduardo Gamero Casado (coordinador), Simplificación del procedimiento administrativo y mejora de la regulación. Una metodología para la eficacia y el derecho a la buena administración. Valencia: Tirant lo Blanch.

PonCE SolÉ, Juli (2001). Deber de buena administración y derecho al procedimiento administrativo debido. Las bases constitucionales del procedimiento administrativo y del ejercicio de la discrecionalidad. Valladolid: Lex Nova.

Rebollo Puig, Manuel (2013). «La actividad inspectora». En Juan José Díez Sánchez (coordinador), Función inspectora. Actas del VIII Congreso de la Asociación Española de profesores de Derecho Administrativo. Alicante, 8 y 9 de febrero de 2013. Madrid: INAP.

Rivero Ortega, Ricardo (2012). «Capítulo II. La obligación de resolver». En Tomás Quintana López (director) y Marcos Anabelén Casares (coordinador), Silencio ad- 
ministrativo. Estudio general y procedimientos sectoriales. Valencia: Tirant lo Blanch. Rivero Ysern, Enrique (2016). "Capítulo VI. Obligación de resolver y silencio administrativo». En Ricardo Rivero Ortega, María Dolores Calvo Sánchez y Marcos Fernando Pablo (directores), Instituciones de Procedimiento Administrativo Común. Novedades de la Ley 39/2015. Lisboa: Juruá.

Santamaría Pastor, Juan Alfonso (2015). «Los proyectos de Ley de Procedimiento Administrativo Común y de Régimen Jurídico: una primera evaluación».Documentación Administrativa, 2. Disponible en https://bit.ly/2Osb4EJ.

\section{Sobre el autor}

Humberto Gosálbez Pequeño es doctor en Derecho y profesor titular de Derecho Administrativo de la Universidad de Córdoba (España). Es asimismo director de la Revista Internacional de Derecho del Turismo (RIDETUR), cuyo sitio web es https:// www.uco.es/ucopress/ojs/index.php/ridetur/index. Su dirección postal es Facultad de Ciencias del Trabajo, C/Adarve, 30.14001-Córdoba (España). Su correo electrónico es adıgopeh@uco.es y su teléfono de contacto es el 665057264. 